\title{
Additive Manufacturing of Two-dimensional Conductive Metal-Organic Framework with Multidimensional Hybrid Architectures for High-Performance Energy Storage
}

Jingxin $\mathrm{Zhao}^{\mathrm{a}+}$, Yan Zhang ${ }^{\mathrm{b}+}$, Hongyu $\mathrm{Lu}^{\mathrm{c}+}$, Yafei $\mathrm{Wang}^{\mathrm{b}+}$, Xu Dong Liu ${ }^{\mathrm{d}}$, Hirbod Maleki Kheimeh Sari ${ }^{\mathrm{c}}$, Jianhong Peng ${ }^{\mathrm{c} *}$, Shufan Chen ${ }^{\mathrm{d}}$, Xifei Li ${ }^{\mathrm{c} *}$, Yongjun Zhang ${ }^{\mathrm{b}}$, Xueliang Sun ${ }^{\mathrm{e} *}$, and Bingang $\mathrm{Xu}^{\mathrm{a} *}$

a. Nanotechnology Center, Institute of Textiles and Clothing, The Hong Kong Polytechnic University, Hung Hom, Kowloon, Hong Kong, 999077, P. R. China

b. Key Laboratory of Functional Polymer Materials and State Key Laboratory of Medical Chemical Biology, Institute of Polymer Chemistry, College of Chemistry, Nankai University, Tianjin, 300071, P. R. China

c. Institute of Advanced Electrochemical Energy, Xi'an University of Technology, Xi'an, Shaanxi, 710048, P. R. China

d. Centre of Laser Fusion, China Academy of Engineering Physics, Mianyang, 621900, P. R. China

e. Department of Mechanical and Materials Engineering, University of Western Ontario, London, Ontario, N6A5B9, Canada

[*] Email: tcxubg@polyu.edu.hk

xsun9@uwo.ca

xfli2011@hotmail.com

pjhhj@sohu.com

$\left.{ }^{+}\right]$These authors contributed equally to this work. 


\section{Table of Contents for Supplemental Information}

\section{Supplemental Experimental Details}

\section{Supporting Notes}

2.1 Structural characterization (SEM, TEM, XRD, Raman and XPS) of the VN electrode materials

2.2 Electrochemical performance of the as-prepared C60@VNNWs@rGO microlattice electrode

\section{Supporting Figures}

Figure S1. Mechanical performance of (a) 3D-printed Cu-THQ@CNTs@rGO microlattices, (b) 3D-printed Cu/Ni-THQ@CNTs@rGO microlattices and (c) 3D-printed Cu/Co-THQ@CNTs@rGO microlattices until 60 \% compression for 10 cycles. (d) Mechanical performance of 3D-printed C60@VNNWs@GO microlattices until 50 \% compression for 10 cycles.

Figure S2. (a-c) SEM images, and (d-f) HRTEM images of the 2D M-THQ CMOF $(\mathrm{M}=\mathrm{Cu}$, $\mathrm{Cu} / \mathrm{Co}$ and $\mathrm{Cu} / \mathrm{Ni}$ ). Insets: magnified pictures of the selected areas.

Figure S3. (a, b) PXRD patterns of $\mathrm{Cu}-\mathrm{THQ}$ and $\mathrm{Cu} / \mathrm{Ni}-\mathrm{THQ}$. (c, d) Graphic representation of $\mathrm{Cu}-\mathrm{THQ}$ and $\mathrm{Cu} / \mathrm{Ni}-\mathrm{THQ}$. (e, f) Unit-cell structure of $\mathrm{Cu}-\mathrm{THQ}$ and $\mathrm{Cu} / \mathrm{Ni}-\mathrm{THQ}$.

Figure S4. (a) Apparent viscosity as a function of shear rate for the ink. (b) Storage modulus $\left(G^{\prime}\right)$ and loss modulus $\left(G^{\prime \prime}\right)$ as a function of shear stress for the ink. (c, d) Apparent viscosity as a function of shear rate, and storage modulus $\left(\mathrm{G}^{\prime}\right)$ and loss modulus $\left(\mathrm{G}^{\prime \prime}\right)$ as a function of shear stress for the ink after 4 weeks of storage. (e, f) Cyclic shear-thinning experiment of the ink showing viscosity, storage $\left(\mathrm{G}^{\prime}\right)$ and loss $\left(\mathrm{G}^{\prime \prime}\right)$ modulus response.

Figure S5. (a) Apparent viscosity as a function of shear rate for the ink. (b) Storage modulus 
$\left(\mathrm{G}^{\prime}\right)$ and loss modulus $\left(\mathrm{G}^{\prime \prime}\right)$ as a function of shear stress for the ink. (c, d) Apparent viscosity as a function of shear rate, and storage modulus $\left(\mathrm{G}^{\prime}\right)$ and loss modulus $\left(\mathrm{G}^{\prime \prime}\right)$ as a function of shear stress for the ink after 4 weeks of storage. (e, f) Cyclic shear-thinning experiment of the ink showing viscosity, storage $\left(\mathrm{G}^{\prime}\right)$ and loss $\left(\mathrm{G}^{\prime \prime}\right)$ modulus response.

Figure S6. (a) Apparent viscosity as a function of shear rate for the ink. (b) Storage modulus $\left(G^{\prime}\right)$ and loss modulus $\left(G^{\prime \prime}\right)$ as a function of shear stress for the ink. (c, d) Apparent viscosity as a function of shear rate, and storage modulus $\left(\mathrm{G}^{\prime}\right)$ and loss modulus $\left(\mathrm{G}^{\prime \prime}\right)$ as a function of shear stress for the ink after 4 weeks of storage. (e, f) Cyclic shear-thinning experiment of the ink showing viscosity, storage $\left(\mathrm{G}^{\prime}\right)$ and loss $\left(\mathrm{G}^{\prime \prime}\right)$ modulus response.

Figure S7. Characterization of the as-prepared VN nanowires. (a) SEM image. (b) High-resolution TEM image; inset is the low-magnification TEM image. (c) XRD pattern. (d) Raman spectra. XPS spectra of (e) V 2p and (f) O 1s.

Figure S8. (a, b) SEM images, (c) LCSM image and (d) $\mathrm{N}_{2}$ adsorption/desorption isotherm of the 3D-printed Cu-THQ@CNTs@rGO microlattices and its gradient porous structure.

Figure S9. (a, b) SEM images, (c) LCSM image and (d) $\mathrm{N}_{2}$ adsorption/desorption isotherm of the 3D-printed Cu/Ni-THQ@CNTs@rGO microlattices and its gradient porous structure.

Figure S10. (a, b) SEM images, (c-f) EDX images of the V, O, N and C elements in (a), (g, h) LCSM images and (i) $\mathrm{N}_{2}$ adsorption/desorption isotherm of the 3D-printed C60@VNNWs@rGO microlattices and its gradient porous structure.

Figure S11. Photographs of the as-fabricated Cu/Co-THQ@CNTs@rGO microlattice electrode with 4 layer (a), 8 layer (b), 12 layer (c) and 16 layer (d).

Figure S12. $\mathrm{N}_{2}$ adsorption/desorption isotherm of the 3D-printed Cu/Co-THQ@CNTs@rGO microlattices and its gradient porous structure.

Figure S13. Cycling performance of the 3D-printed Cu/Co-THQ@CNTs@rGO microlattice 
electrode at $0.1 \mathrm{~A} \mathrm{~g}^{-1}$

Figure S14. Nyquist plots of the 3D-printed Cu/Co-THQ@CNTs@rGO microlattice electrodes with different layers.

Figure S15. (a) CV curves of the 3D-printed Cu/Co-THQ@CNTs@rGO microlattice electrodes with different layers at $0.1 \mathrm{mV} \mathrm{s}^{-1}$. (b) $\mathrm{CV}$ curves of the 3D-printed Cu/Co-THQ@CNTs@rGO microlattice electrode at various scan rates from 0.05 to $0.2 \mathrm{mV}$ $\mathrm{S}^{-1}$

Figure S16. Electrochemical performance of the C60@VNNWs@rGO microlattice electrode. (a) $\mathrm{CV}$ curves of the 3D-printed electrodes with different layers at $0.5 \mathrm{mV} \mathrm{s}^{-1}$. (b) The typical charging/discharging of the 3D-printed electrodes with different layers with the potential window of $0.01-3 \mathrm{~V}\left(\mathrm{vs} \mathrm{Li} / \mathrm{Li}^{+}\right)$at $0.2 \mathrm{~g}^{-1}$. (c) Nyquist plots of the 3D-printed electrodes with different layers. (d) CV curves of the 3D-printed electrode with 12 layers at various scan rates from 0.5 to $10 \mathrm{mV} \mathrm{s}^{-1}$. (e-h) Rate capability of the 3D-printed electrodes with different layers $\left(4,8,12\right.$ and 16 layers) at various current densities ranging from 0.1 to $5 \mathrm{~A} \mathrm{~g}^{-1}$, respectively. (i) Cycling performance of the 3D printed electrodes with different layers at $5 \mathrm{~A} \mathrm{~g}^{-1}$.

Figure S17. (a) The enlarged $\mathrm{Cu}$ K-edge XANES curves of $\mathrm{Cu}-\mathrm{THQ}, \mathrm{Cu} / \mathrm{Co}-\mathrm{THQ}$ and $\mathrm{Cu} / \mathrm{Ni}$-THQ. (b) Ni K-edge XANES spectra of $\mathrm{Cu} / \mathrm{Ni}$-THQ and references. (c) Co K-edge XANES spectra of $\mathrm{Cu} / \mathrm{Co}-\mathrm{THQ}$ and references.

Figure S18. The typical fitting curve of the EXAFS signal in $\mathrm{Cu} \mathrm{K}$-edge for (a) $\mathrm{Cu}-\mathrm{THQ}$ and (b) $\mathrm{Cu} / \mathrm{Co}$-THQ. The typical fitting curve of the EXAFS signal in (c) Ni K-edge for $\mathrm{Cu} / \mathrm{Ni}$-THQ and (d) Co K-edge for Cu/Co-THQ. (e, f) Wavelet transform (WT) contour plots of $\mathrm{Cu} / \mathrm{Co}-\mathrm{THQ}, \mathrm{Cu} / \mathrm{Ni}-\mathrm{THQ}$ and references.

Figure S19. WT contour plots of $\mathrm{Cu}-\mathrm{THQ}, \mathrm{Cu} / \mathrm{Ni}-\mathrm{THQ}, \mathrm{Cu} / \mathrm{Co}-\mathrm{THQ}$ and references.

Figure S20. Density of states for (a) Cu-THQ and $\mathrm{Cu} / \mathrm{Ni}$-THQ. Energy barrier profile of $\mathrm{Li}^{+}$ 
migration through (c) $\mathrm{Cu}-\mathrm{THQ}$ and (d) $\mathrm{Cu} / \mathrm{Ni}-\mathrm{THQ}$. The insets are the corresponding migration process.

Figure S21. The digital photo of the 3D-printed LIHCs device.

Figure S22. (a) CV curves of the 3D-printed LIHCs device at various scan rates from 2 to 50 $\mathrm{mV} \mathrm{s}^{-1}$. (b) Nyquist plot of the 3D-printed LIHCs device.

Table S1. Structural parameters of the sample obtained from the XAFS fitting at $\mathrm{Cu}$ K-edge.

Table S2. Structural parameters of the sample obtained from the XAFS fitting at Co K-edge.

Table S3. Structural parameters of the sample obtained from the XAFS fitting at Ni K-edge.

Table S4. The electrical conductivity of $\mathrm{Cu}-\mathrm{THQ}, \mathrm{Cu} / \mathrm{Co}-\mathrm{THQ}$ and $\mathrm{Cu} / \mathrm{Ni}-\mathrm{THQ}$. 


\section{Supplemental Experimental Details}

\subsection{Synthesis of M-THQ CMOFs $(\mathrm{M}=\mathrm{Cu}, \mathrm{Cu} / \mathrm{Co}$ or $\mathrm{Cu} / \mathrm{Ni})$}

$\mathrm{Cu}$-THQ was synthesized according to the previous reports. ${ }^{1}$ In a typical fabrication process, tetrahydroxy-1,4-quinone (THQ) (200 mg) was dissolved in $50 \mathrm{ml}$ of degassed $\mathrm{H}_{2} \mathrm{O}$ under $\mathrm{N}_{2}$ atmosphere. A mixture of $\mathrm{Cu}\left(\mathrm{NO}_{3}\right)_{2} \cdot 2.5 \mathrm{H}_{2} \mathrm{O}(253 \mathrm{mg})$ and ethylenediamine (280 $\mu \mathrm{L}$ ) in $100 \mathrm{~mL}$ of degassed $\mathrm{H}_{2} \mathrm{O}$ was transferred to the THQ solution under vigorous stirring. The reaction was conducted under stirring for $24 \mathrm{~h}$ at $85^{\circ} \mathrm{C}$. The as-prepared product was centrifuged at $8000 \mathrm{rpm}$ and then washed with deionized $\mathrm{H}_{2} \mathrm{O}$ several times and finally vacuum-dried overnight in an oven at $80{ }^{\circ} \mathrm{C}$. In addition, $\mathrm{Cu} / \mathrm{Co}$-THQ and $\mathrm{Cu} / \mathrm{Ni}$-THQ were obtained by utilizing half the amount of $\mathrm{Cu}\left(\mathrm{NO}_{3}\right)_{2} \cdot 2.5 \mathrm{H}_{2} \mathrm{O}(126.5 \mathrm{mg})$ with $\mathrm{Co}\left(\mathrm{NO}_{3}\right)_{2} \cdot 6 \mathrm{H}_{2} \mathrm{O}$ $(126.5 \mathrm{mg})$ and $\mathrm{Ni}\left(\mathrm{NO}_{3}\right)_{2} \bullet 6 \mathrm{H}_{2} \mathrm{O}(126.5 \mathrm{mg})$, respectively.

\subsection{Synthesis of porous VN nanowires (VNNWs)}

Porous VNNWs was prepared according to the previous publications. ${ }^{2}$ In a typical fabrication procedure, $0.2 \mathrm{~g} \mathrm{NH}_{4} \mathrm{VO}_{3}$ was added to $40 \mathrm{~mL}$ deionized $\mathrm{H}_{2} \mathrm{O}$, the $\mathrm{PH}$ value of solution was regulated to $2-3$ by slowly adding $\mathrm{HCl}$, and then transferred to a $50 \mathrm{~mL}$ Teflon-lined autoclave. The autoclave was heated to $160^{\circ} \mathrm{C}$, and the as-prepared product was washed using deionized water and then vacuum-dried at $80{ }^{\circ} \mathrm{C}$ overnight after the autoclave was cooled down to room temperature. Finally, the as-obtained sample was annealed at 550 ${ }^{\circ} \mathrm{C}$ for $1 \mathrm{~h}$ in $\mathrm{Ar} / \mathrm{NH}_{3}$ atmosphere.

\subsection{Synthesis of GO Sheets}

GO sheets were fabricated from raw graphite powder by a modified Hummers' method. ${ }^{3}$

\subsection{Fabrication of the Inks}

To obtain the M-THQ@CNTs@GO cathode ink $(\mathrm{M}=\mathrm{Cu}, \mathrm{Cu} / \mathrm{Co}$ and $\mathrm{Cu} / \mathrm{Ni}), 200 \mathrm{mg}$ 
GO, $50 \mathrm{mg}$ SWCNTs and $40 \mathrm{mg}$ electrochemical active electrode materials (Cu-THQ, $\mathrm{Cu} / \mathrm{Co}-\mathrm{THQ}$ and $\mathrm{Cu} / \mathrm{Ni}$-THQ) were dispersed in $50 \mathrm{~mL}$ deionized water, shaken for $2 \mathrm{~h}$ by a rocking device. To achieve the C60@VNNWs@GO anode ink, 200 mg GO, 40 mg C60 and $40 \mathrm{mg}$ VNNWs were dispersed in $50 \mathrm{~mL}$ deionized water, shaken for $2 \mathrm{~h}$ by a rocking device.

\subsection{D-printing process}

A Self-built multi-axis micropositioning configuration (Prusa i3) was utilized for 3D-printing with the nozzle modified into screw extrusion. All the electrode inks were housed in a $1 \mathrm{~mL}$ customized precision feeder with the nozzle size of $230 \mu \mathrm{m}$. The typical printing speed was $5 \mathrm{~mm} \mathrm{~s}^{-}{ }^{1}$ and the whole process was controlled by G-code. To facilitate the removal of the microlattice electrodes, the printing was performed on a flat copper foil. For all of the electrode inks, the 3D-printed patterns were immersed in liquid nitrogen after printing and then freeze-dried for two days to obtain aerogels. The 3D printed Cu-THQ@CNTs@GO, Cu/Co-THQ@CNTs@GO, Cu/Ni-THQ@CNTs@GO and C60@VNNWs@GO hybrid microlattice aerogels were chemical reduced in hydrazine hydrate atmosphere at $80{ }^{\circ} \mathrm{C}$ for $8 \mathrm{~h}$ and thermally treated at $650{ }^{\circ} \mathrm{C}$ for $3 \mathrm{~h}$ in Ar atmosphere to obtain $\mathrm{Cu}-\mathrm{THQ} @ \mathrm{CNTs} @ \mathrm{rGO}$, Cu/Co-THQ@CNTs@rGO,Cu/Ni-THQ@CNTs@rGO and C60@VNNWs@rGO hybrid microlattice aerogels, respectively. For all the hybrid microlattice aerogels, the spacing (L) between the cylindrical rods center was $600 \mu \mathrm{m}$. The layer thickness of all the 3D-printed hybrid microlattice aerogels was $150 \mu \mathrm{m}$ and the layer count was 1 to 16 . For M-THQ@CNTs@rGO cathode with 4, 8, 12 and 16 layers, the total mass loading of 3.72, 7.45, 11.18 and 14.91 mg are achieved, respectively. For C60@VNNWs@rGO anode with 2, 4, 6 and 8 layers, the total mass loading of 1.86, 3.72, 5.59 and $7.45 \mathrm{mg}$ are obtained, respectively.

\subsection{Characterization}


XRD measurements of the samples were executed by an X-ray diffractometer using $\mathrm{Cu}$ $\mathrm{K} \alpha$ radiation (D8 Advance PANalytical X'Pert Pro) from $10^{\circ}$ to $90^{\circ}$. The morphology and microstructures of the as-prepared products were detected by a field-emission scanning electron microscope (FESEM) (S-4800) and transmission electron microscope (TEM) (Tecnai G2 F20 S-TWIN). X-ray photoelectron spectroscopy (XPS) of the as-fabricated samples was performed using an ESCALAB_250Xi system. The binding energies in the XPS analysis were corrected with referencing $\mathrm{C} 1 \mathrm{~s}$ to $284.6 \mathrm{eV}$. Nitrogen adsorption/desorption measurements were carried out using an ASAP 2020 volumetric adsorption analyzer (Micromeritics, USA) at $77 \mathrm{~K}$. The order channel structures of the 3D-printed hybrid microlattice aerogels were observed by a laser confocal scanning microscope (LCSM) (KEYENCE VK-X200) and FESEM (S-4800), combined with energy dispersive X-ray spectroscopy (EDX, Oxford X-Max20) for the determination of the element composition. The X-ray absorption spectra $(\mathrm{Cu}, \mathrm{Co}$ and Ni K-edge) were tested in the BL14W1 beamline of the Shanghai Synchrotron Radiation Facility, China, (operated at $3.5 \mathrm{GeV}$ with maximum injection currents of $230 \mathrm{~mA}$ ). The X-ray absorption fine structure (XAFS) data of the samples were collected at room temperature in fluorescence excitation mode using a Lytle detector. $\mathrm{Cu}, \mathrm{CuO}, \mathrm{Co}, \mathrm{CoO}, \mathrm{Ni}$ and $\mathrm{NiO}$ standard samples were used as the reference samples. The UV-Vis diffuse reflectance spectra (DRS) were measured by a UV-Vis spectrophotometer (Lambda 750S).

\subsection{Lithium-ion hybrid supercapacitors (LIHCs) device packaging}

A thin-walled poly(methyl methacrylate) (PMMA) framework is cut by laser, and then placed around the LIHCs device and sealed with PDMS gel (Sylgard 184, Dow Corning, Inc.), cured at $150^{\circ} \mathrm{C}$. The assembled LIHCs device is filled with liquid electrolyte and sealed with additional PDMS.

\subsection{Electrochemical characterization}

All the electrochemical measurements were performed in a glovebox filled with argon. 
Cyclic voltammetry $(\mathrm{CV})$, galvanostatic charge/discharge and electrochemical impedance spectroscopy (EIS) tests were executed using CHI660E (Shanghai, China). The cycle-life tests for half-cell and hybrid cells were performed using a battery test system (land CT2001A model, Wuhan Land Electronics. Ltd.). For the half-cell test, both anode and cathode are immersed in nonaqueous electrolyte (1 M LiPF6 in a 1:1 ratio of ethylene carbonate (EC) and diethyl carbonate (DEC) by volume), and lithium metal was served as both the counter and reference electrodes. For the hybrid cells in liquid electrolyte, the identical measurement is operated again, where M-THQ@CNTs@rGO and C60@VNNWs@rGO were used as the cathode and anode, respectively.

\subsection{Computational methods}

Density functional theory (DFT) calculations were performed by Vienna Ab initio Simulation Package (VASP).,5 Generalized gradient approximation functionals put forward by Perdew, Burke and Ernzerhof, together with projector augmented wave method (PAW-PBE), were used to describe exchange-correlation effects between electrons. ${ }^{6-8}$ All structures were totally relaxed under energy convergence tolerance of $1.0 \times 10^{-5} \mathrm{eV}$ and stress lower than $5.0 \times 10-2 \mathrm{eV} \mathrm{A}^{-1}$ with Monkhorst Brillouin sampling mesh of $2 \times 2 \times 1 .{ }^{9}$ The plane wave energy cut-off was set to be $500 \mathrm{eV}$ for all calculations. The energy barriers of ion transporting in $\mathrm{M}-\mathrm{THQ}(\mathrm{M}=\mathrm{Cu}, \mathrm{Cu} / \mathrm{Co}$ or $\mathrm{Cu} / \mathrm{Ni})$ were characterized by nudged elastic band (NEB) method. ${ }^{10,11}$ Supercell of all THQs for NEB calculations were obtained by enlarging (2 $\mathrm{x} 2 \times 2$ ) of the primitive structures. Single $\Gamma$-point sampling in Brillouin Zone was used. 


\section{Supporting Notes}

\subsection{Structural characterization (SEM, TEM, XRD, Raman and XPS) of the VN electrode materials}

Figure $\mathrm{S} 7 \mathrm{a}$ and $\mathrm{b}$ indicate that the as-fabricated product embraces the one-dimensional nanowire structure with highly porous microstructure, and the length can be reached to tens of micrometers with diameters of $\approx 100 \mathrm{~nm}$. The rich porous structure is beneficial for the penetration of electrolyte into electrode materials with improved capacitance characteristics. The HRTEM image and XRD pattern confirm that the as-prepared product is VN (Figure S7b-c). In addition, the Raman spectra of VN (Figure S7d) shows the typical characteristic peaks of $\mathrm{VO}_{\mathrm{x}}$ deposited on $\mathrm{VN}$, and XPS spectra (Figure S7e-f) confirm the formation of the VN samples.

\subsection{Electrochemical performance of the as-prepared C60@VNNWs@rGO microlattice electrode}

Figure S16a-c show the CV, GCD and EIS curves of the C60@VNNWs@rGO microlattice anode with different layers, while the electrode with 2 layers achieves the optimal electrochemical performance. And the 3D-printed C60@VNNWs@rGO microlattice with 4, 6 and 8 layers exhibit a similar capacity with 2 layers. Based on the principle of the charge match of the Cu/Co-THQ@CNTs@rGO cathode and C60@VNNWs@rGO anode, the C60@VNNWs@rGO electrode with 6 layers is chosen. CV performed on the C60@VNNWs@rGO microlattice anode between 0.01 and 3.0 V is shown in Figure S16d, which indicates its good reversibility. In addition, the C60@VNNWs@rGO microlattice anodes with different layers achieve the rate performances of $71.82 \%, 70.69 \%, 69.47 \%$ and 65.21\%, respectively (Figure S16e-h). Furthermore, the C60@VNNWs@rGO microlattice anodes with different layers deliver the capacity retention of $81.22 \%, 80.46 \%, 79.38 \%$ and 
$76.21 \%$ at the current density of $5 \mathrm{~A} \mathrm{~g}^{-1}$ after 3000 cycles, demonstrating the excellent cycling stability (Figure S16i).

\section{Supporting Figures}
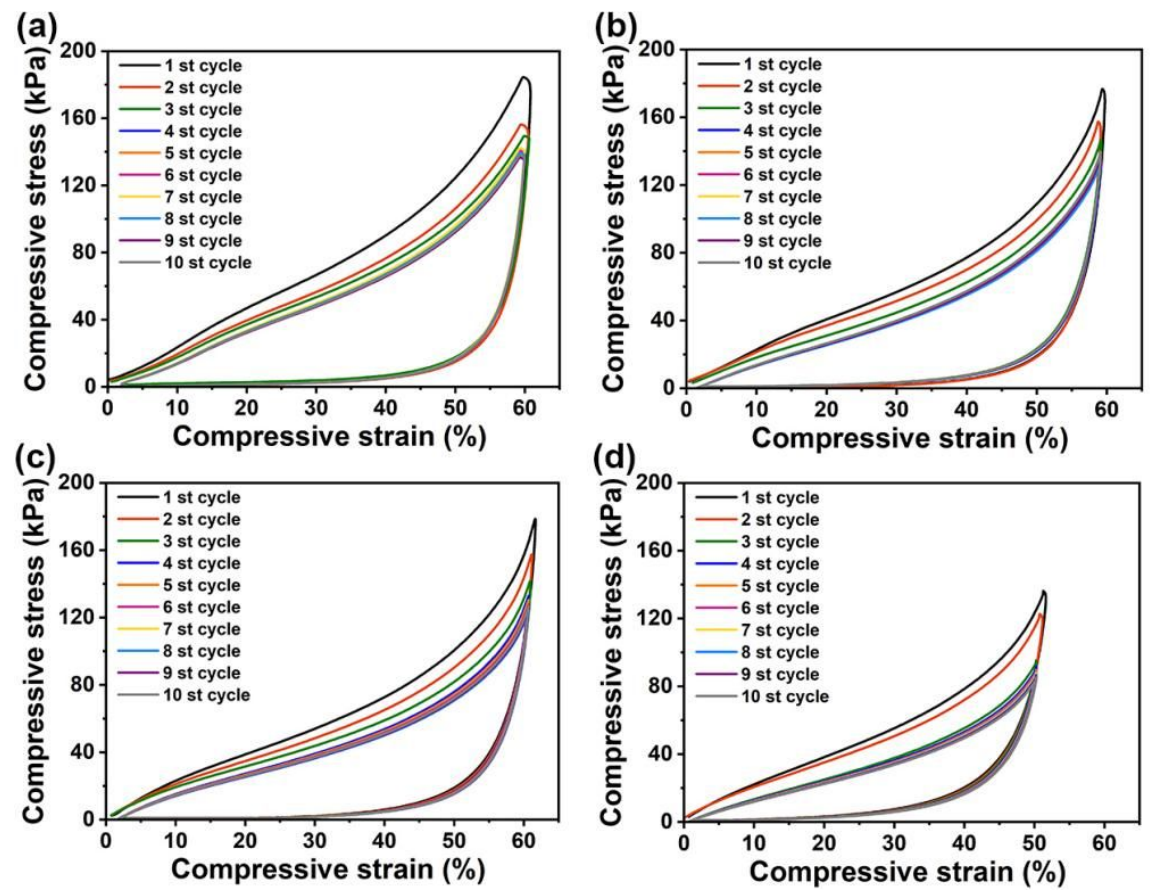

Figure S1. Mechanical performance of (a) 3D-printed Cu-THQ@CNTs@rGO microlattices, (b) 3D-printed Cu/Ni-THQ@CNTs@rGO microlattices and (c) 3D-printed Cu/Co-THQ@CNTs@rGO microlattices until 60 \% compression for 10 cycles. (d) Mechanical performance of 3D-printed C60@VNNWs@GO microlattices until 50 \% compression for 10 cycles. 

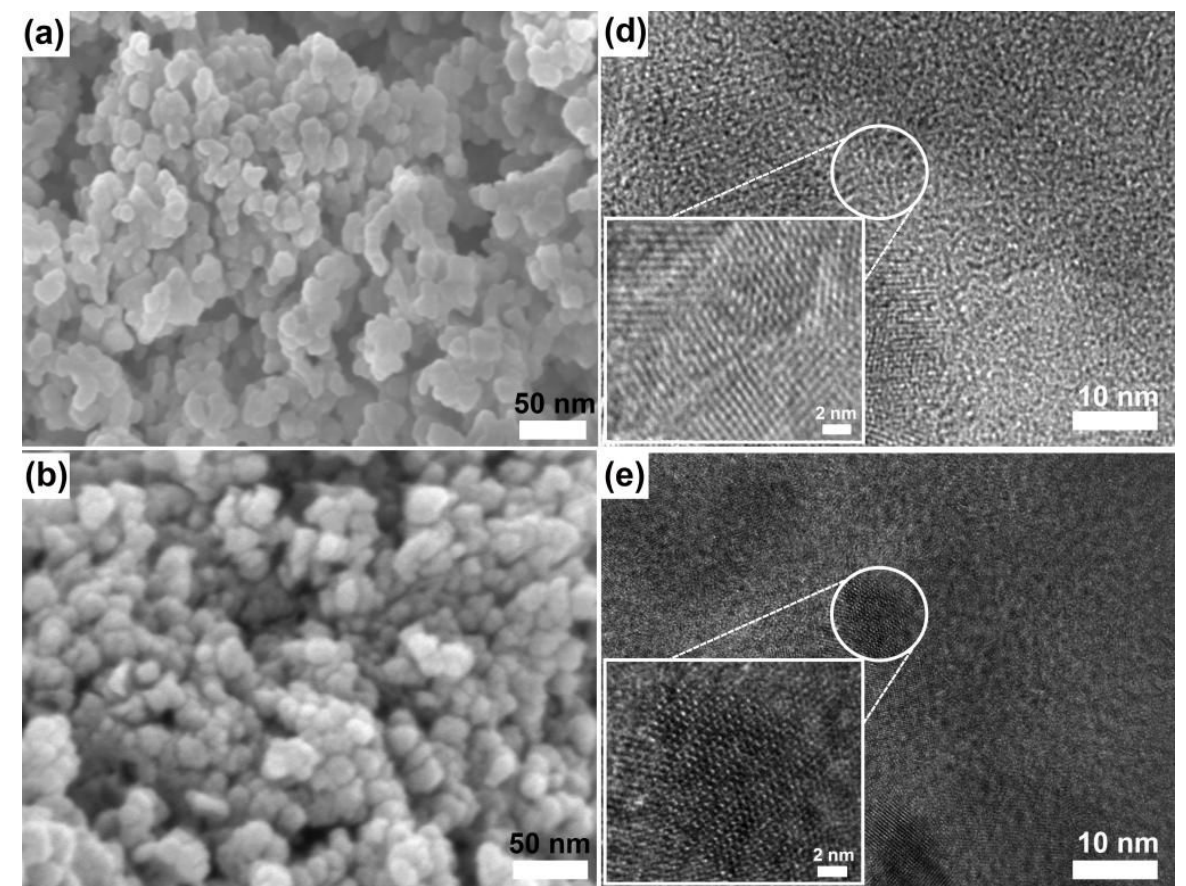

(e)
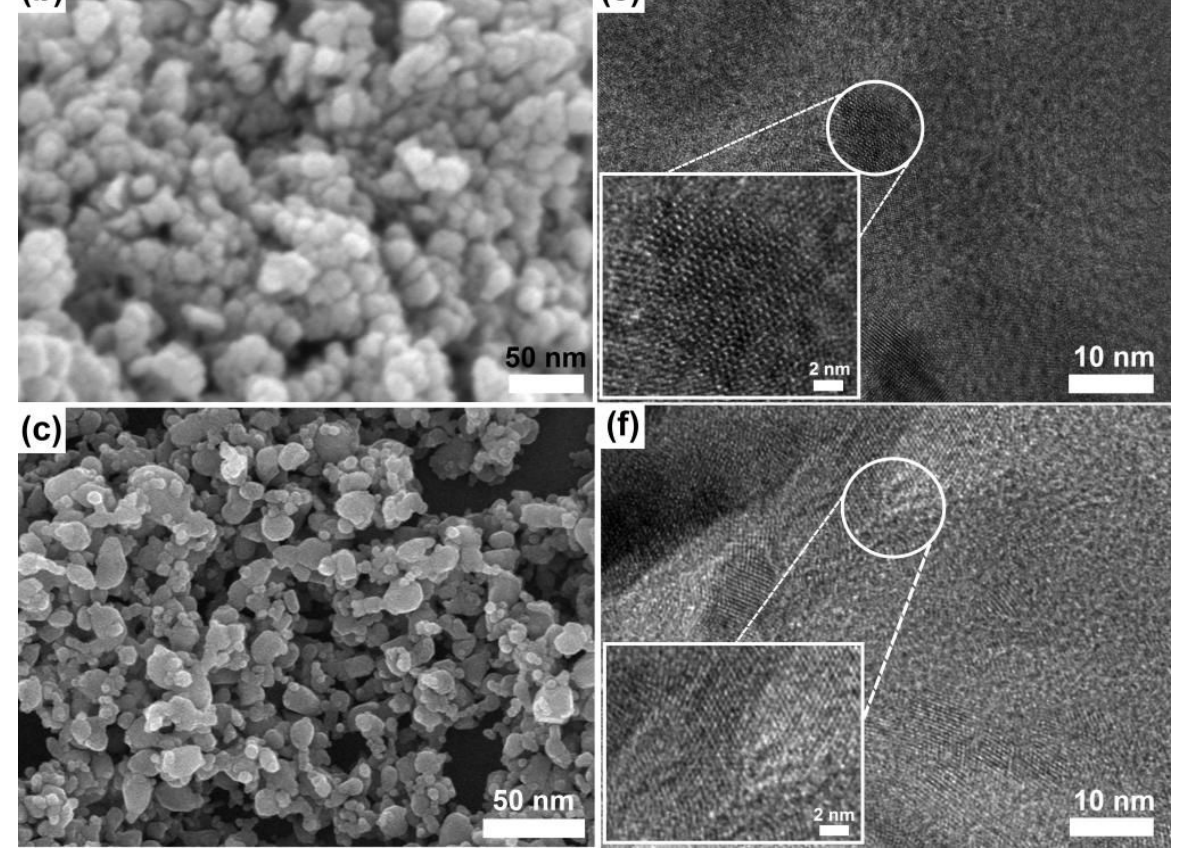

Figure S2. (a-c) SEM images, and (d-f) HRTEM images of the 2D M-THQ CMOF $(\mathrm{M}=\mathrm{Cu}$, $\mathrm{Cu} / \mathrm{Co}$ and $\mathrm{Cu} / \mathrm{Ni}$ ). Insets: magnified pictures of the selected areas. 

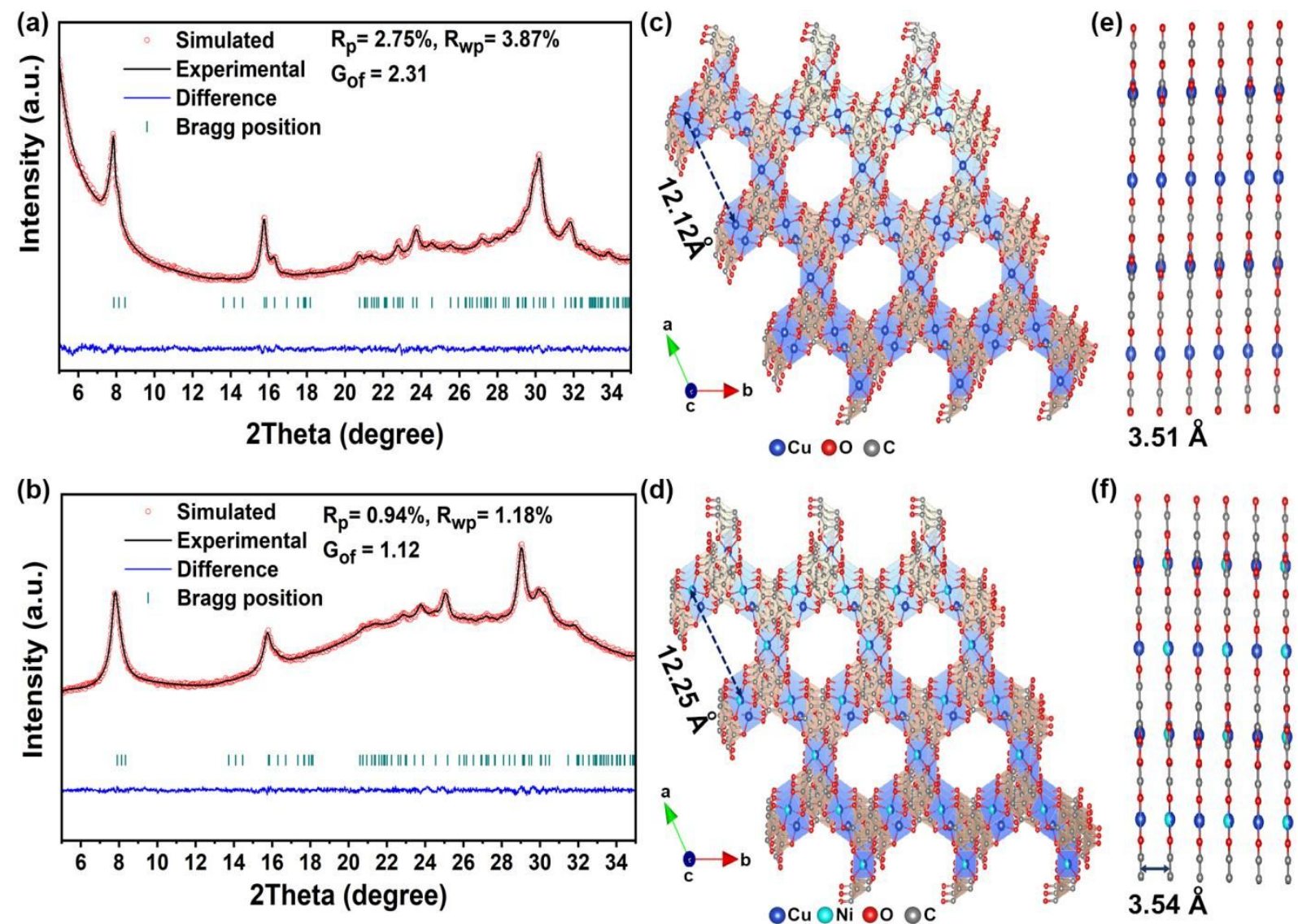

Figure S3. (a, b) PXRD patterns of Cu-THQ and $\mathrm{Cu} / \mathrm{Ni}-\mathrm{THQ}$. (c, d) Graphic representation of $\mathrm{Cu}-\mathrm{THQ}$ and $\mathrm{Cu} / \mathrm{Ni}-\mathrm{THQ}$. (e, f) Unit-cell structure of $\mathrm{Cu}-\mathrm{THQ}$ and $\mathrm{Cu} / \mathrm{Ni}-\mathrm{THQ}$. 

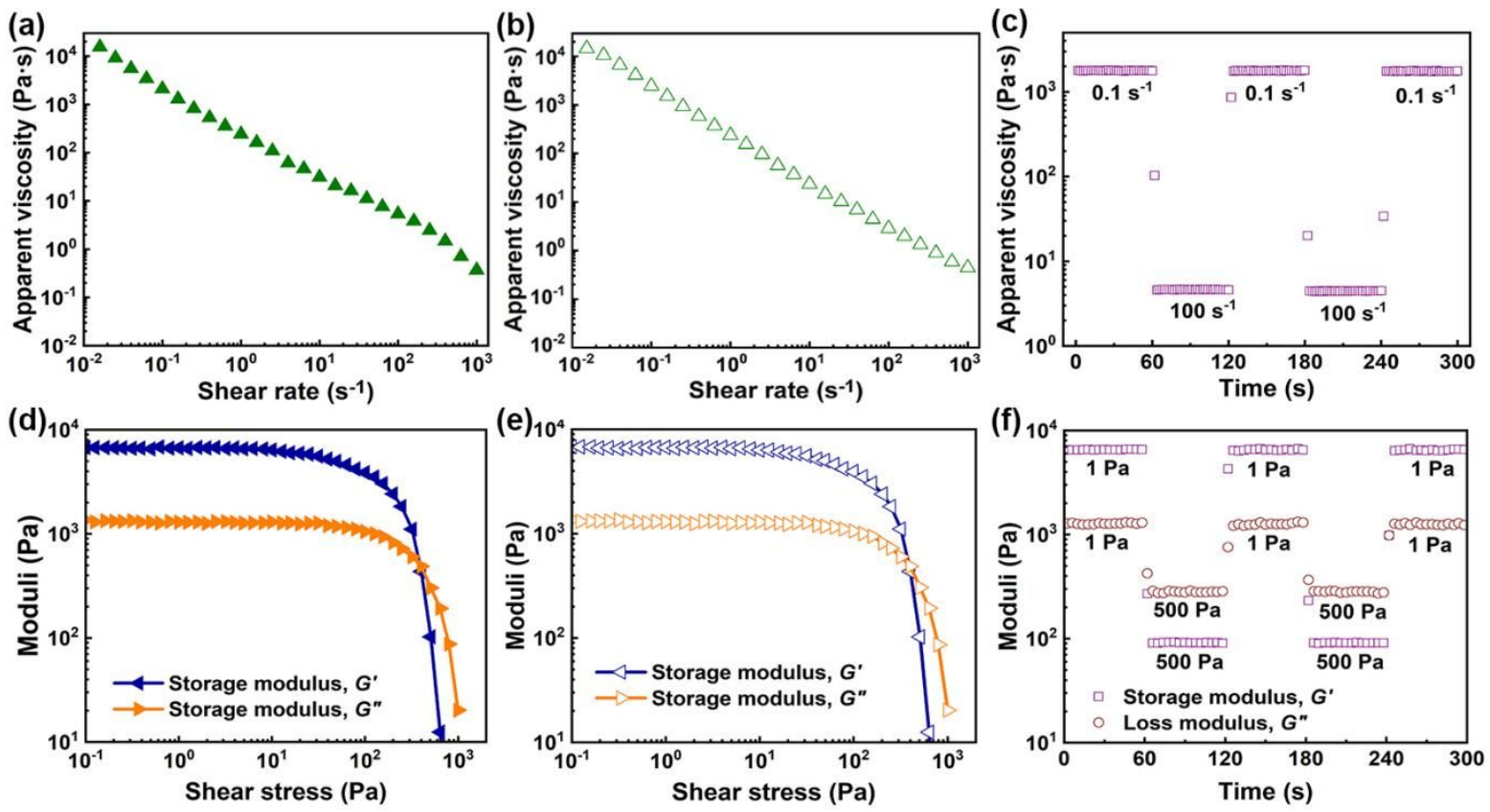

Figure S4. Rheological properties of the Cu-THQ@CNTs@GO ink slurry. (a) Apparent viscosity as a function of shear rate for the ink. (b) Storage modulus $\left(G^{\prime}\right)$ and loss modulus $\left(G^{\prime \prime}\right)$ as a function of shear stress for the ink. (c, d) Apparent viscosity as a function of shear rate, and storage modulus $\left(G^{\prime}\right)$ and loss modulus $\left(G^{\prime \prime}\right)$ as a function of shear stress for the ink after 4 weeks of storage. $(e, f)$ Cyclic shear-thinning experiment of the ink showing viscosity, storage $\left(G^{\prime}\right)$ and loss $\left(G^{\prime \prime}\right)$ modulus response. 

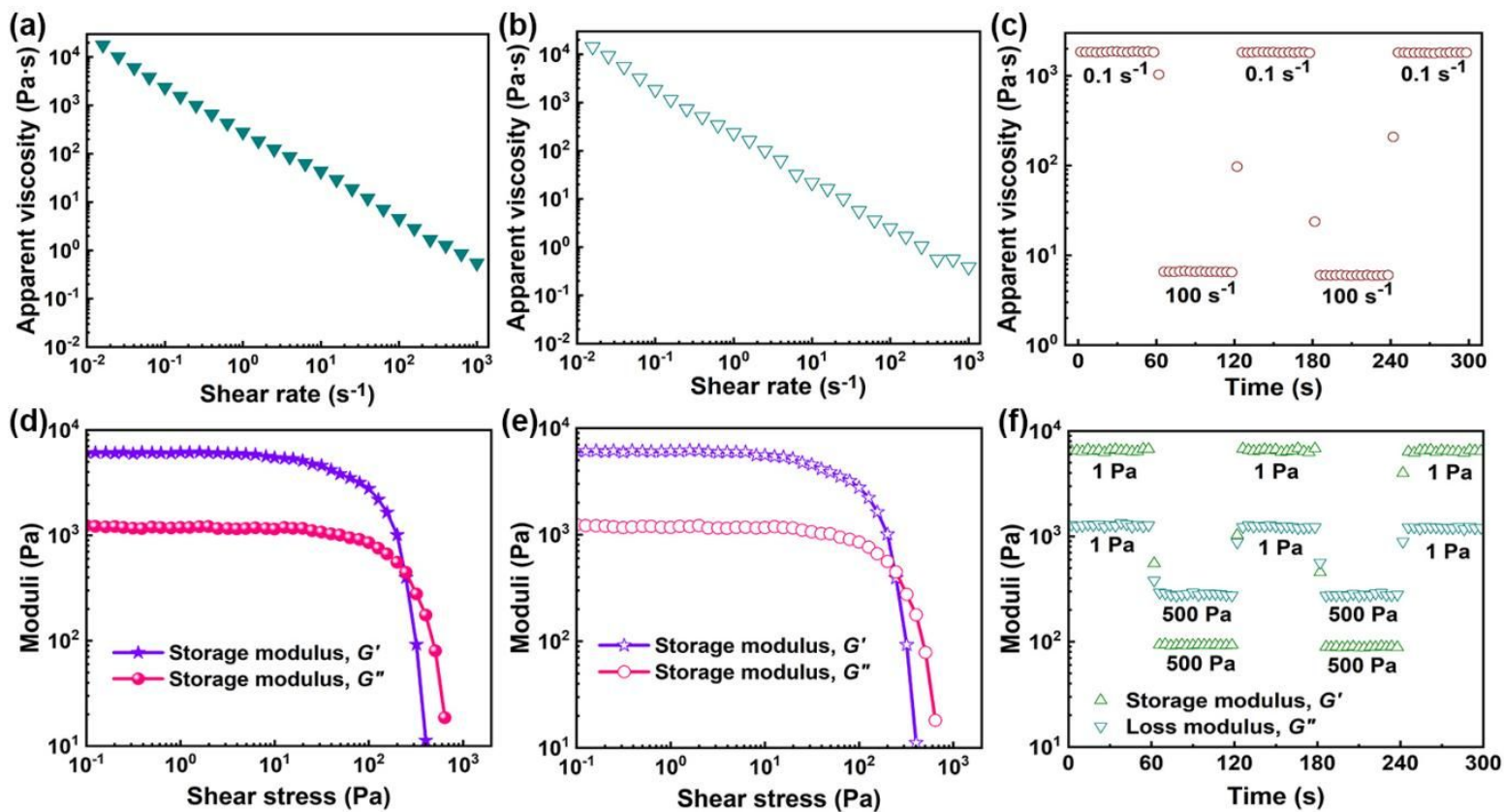

Figure S5. Rheological properties of the Cu/Ni-THQ@CNTs@GO ink slurry. (a) Apparent viscosity as a function of shear rate for the ink. (b) Storage modulus $\left(G^{\prime}\right)$ and loss modulus $\left(G^{\prime \prime}\right)$ as a function of shear stress for the ink. (c, d) Apparent viscosity as a function of shear rate, and storage modulus $\left(G^{\prime}\right)$ and loss modulus $\left(G^{\prime \prime}\right)$ as a function of shear stress for the ink after 4 weeks of storage. (e, f) Cyclic shear-thinning experiment of the ink showing viscosity, storage $\left(G^{\prime}\right)$ and loss $\left(G^{\prime \prime}\right)$ modulus response. 

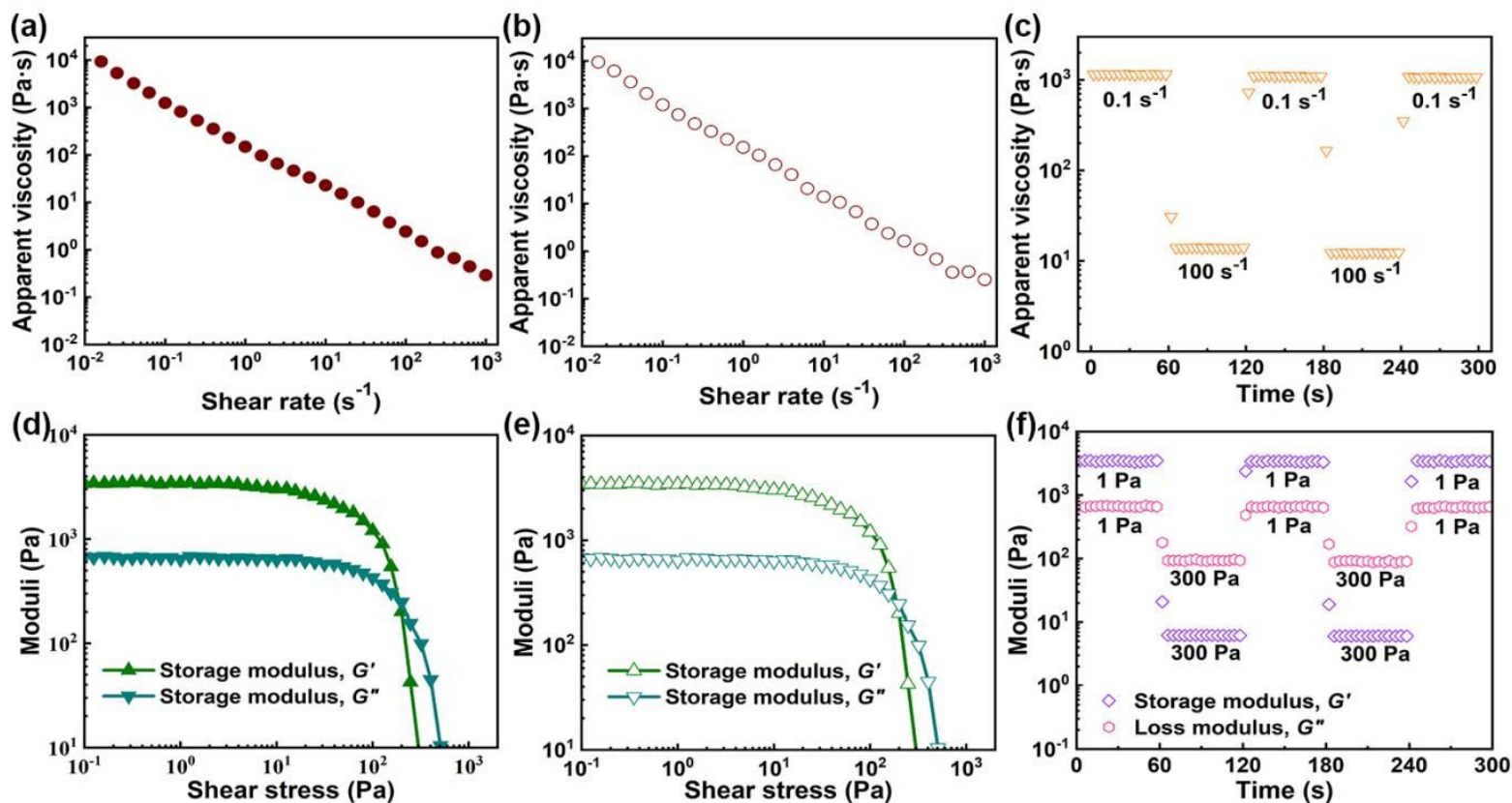

Figure S6. Rheological properties of the C60@VNNWs@GO ink slurry. (a) Apparent viscosity as a function of shear rate for the ink. (b) Storage modulus $\left(G^{\prime}\right)$ and loss modulus $\left(G^{\prime \prime}\right)$ as a function of shear stress for the ink. (c, d) Apparent viscosity as a function of shear rate, and storage modulus $\left(G^{\prime}\right)$ and loss modulus $\left(G^{\prime \prime}\right)$ as a function of shear stress for the ink after 4 weeks of storage. (e, f) Cyclic shear-thinning experiment of the ink showing viscosity, storage $\left(G^{\prime}\right)$ and loss $\left(G^{\prime \prime}\right)$ modulus response. 

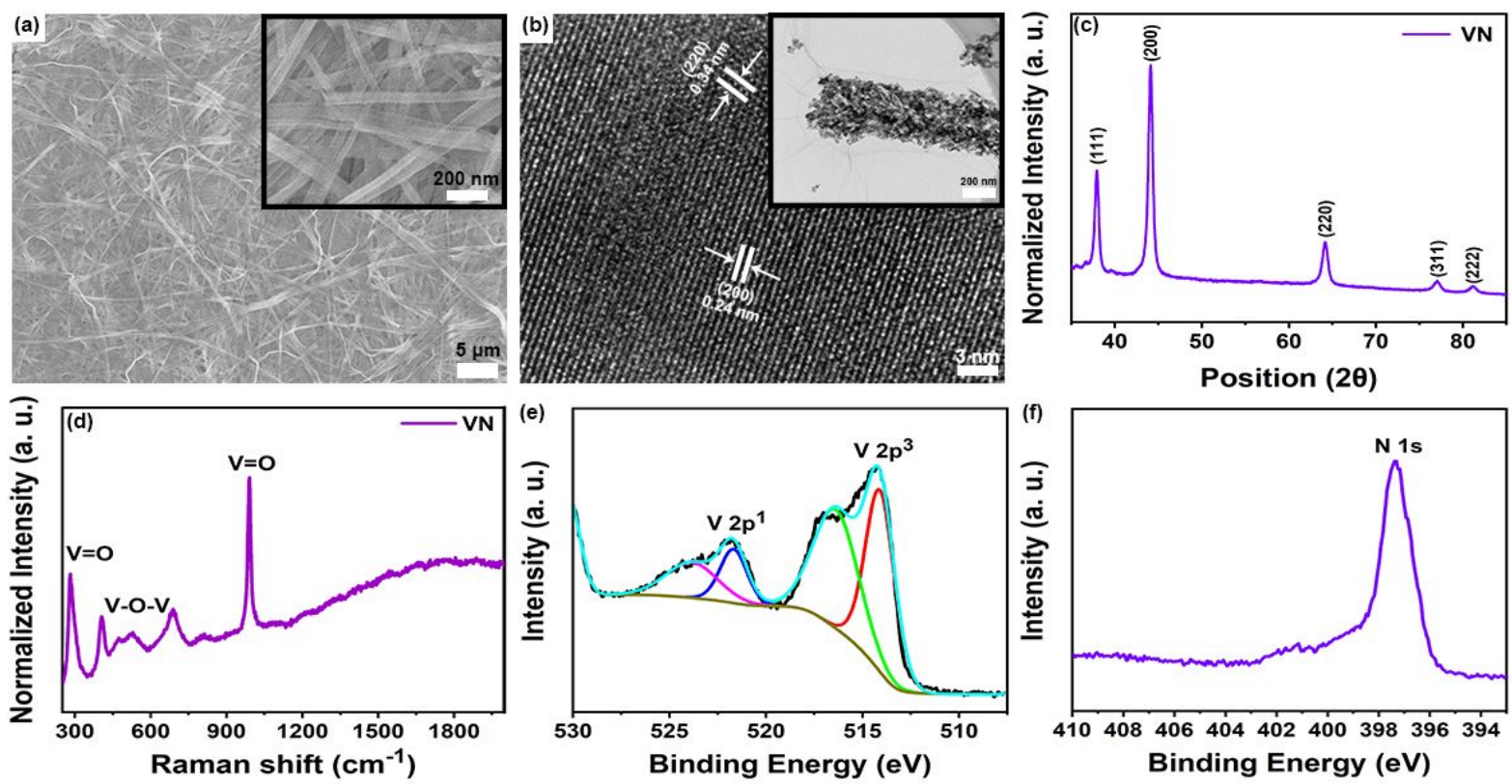

Figure S7. Characterization of the as-prepared VN nanowires. (a) SEM image. (b) High-resolution TEM image; inset is the low-magnification TEM image. (c) XRD pattern. (d) Raman spectra. XPS spectra of (e) V 2p and (f) O 1s. 

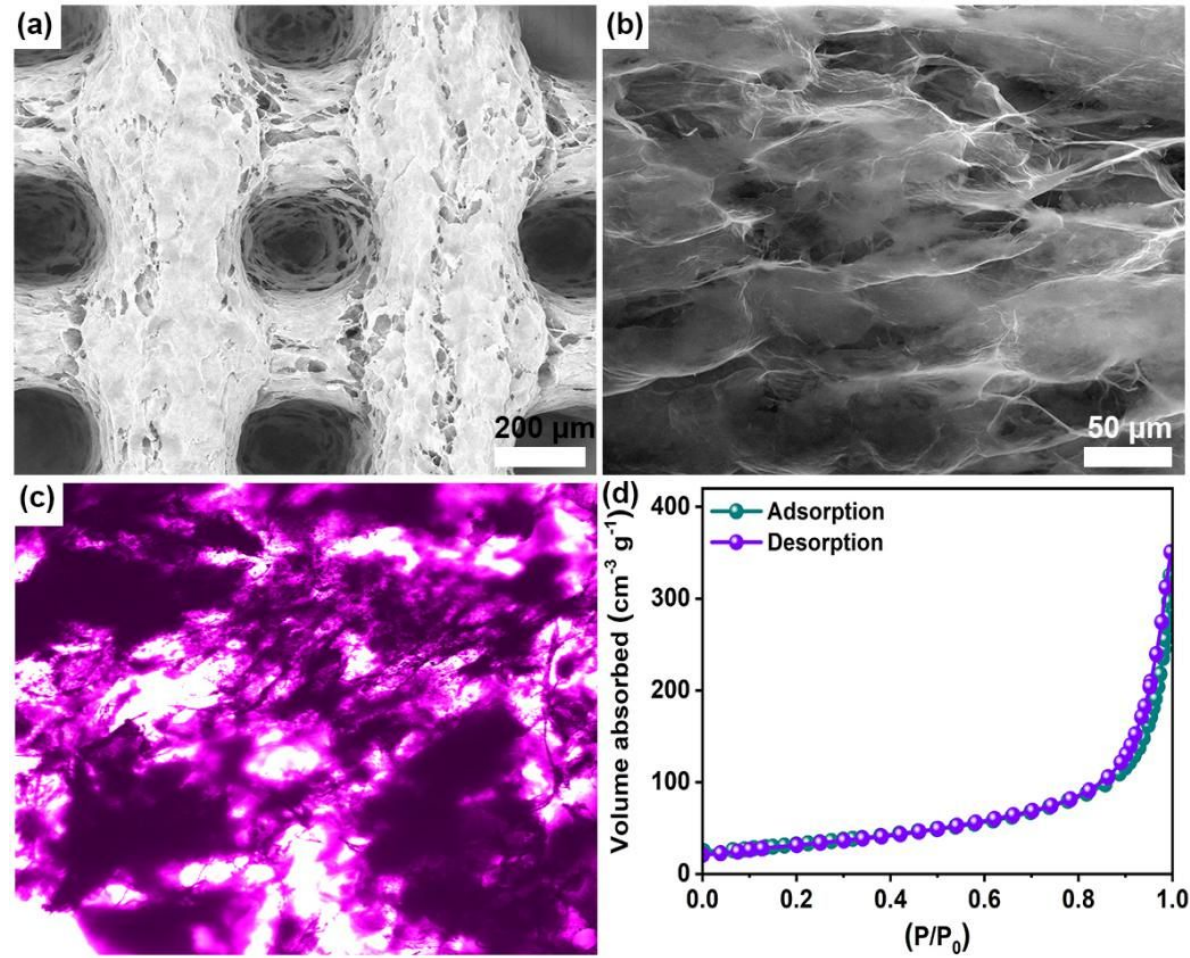

Figure S8. (a, b) SEM images, (c) LCSM image and (d) $\mathrm{N}_{2}$ adsorption/desorption isotherm of the 3D-printed Cu-THQ@CNTs@rGO microlattices and its gradient porous structure. 

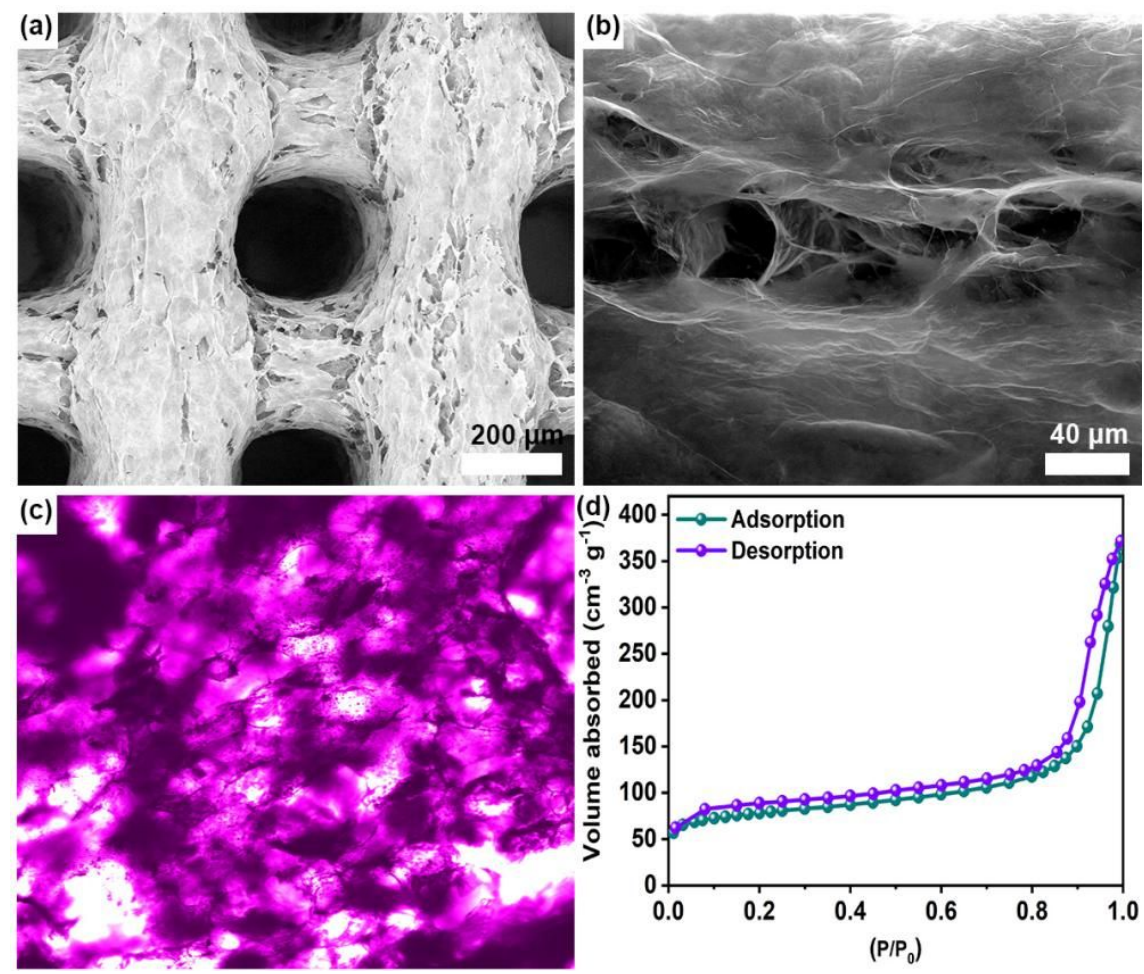

Figure S9. (a, b) SEM images, (c) LCSM image and (d) $\mathrm{N}_{2}$ adsorption/desorption isotherm of the 3D-printed Cu/Ni-THQ@CNTs@rGO microlattices and its gradient porous structure. 

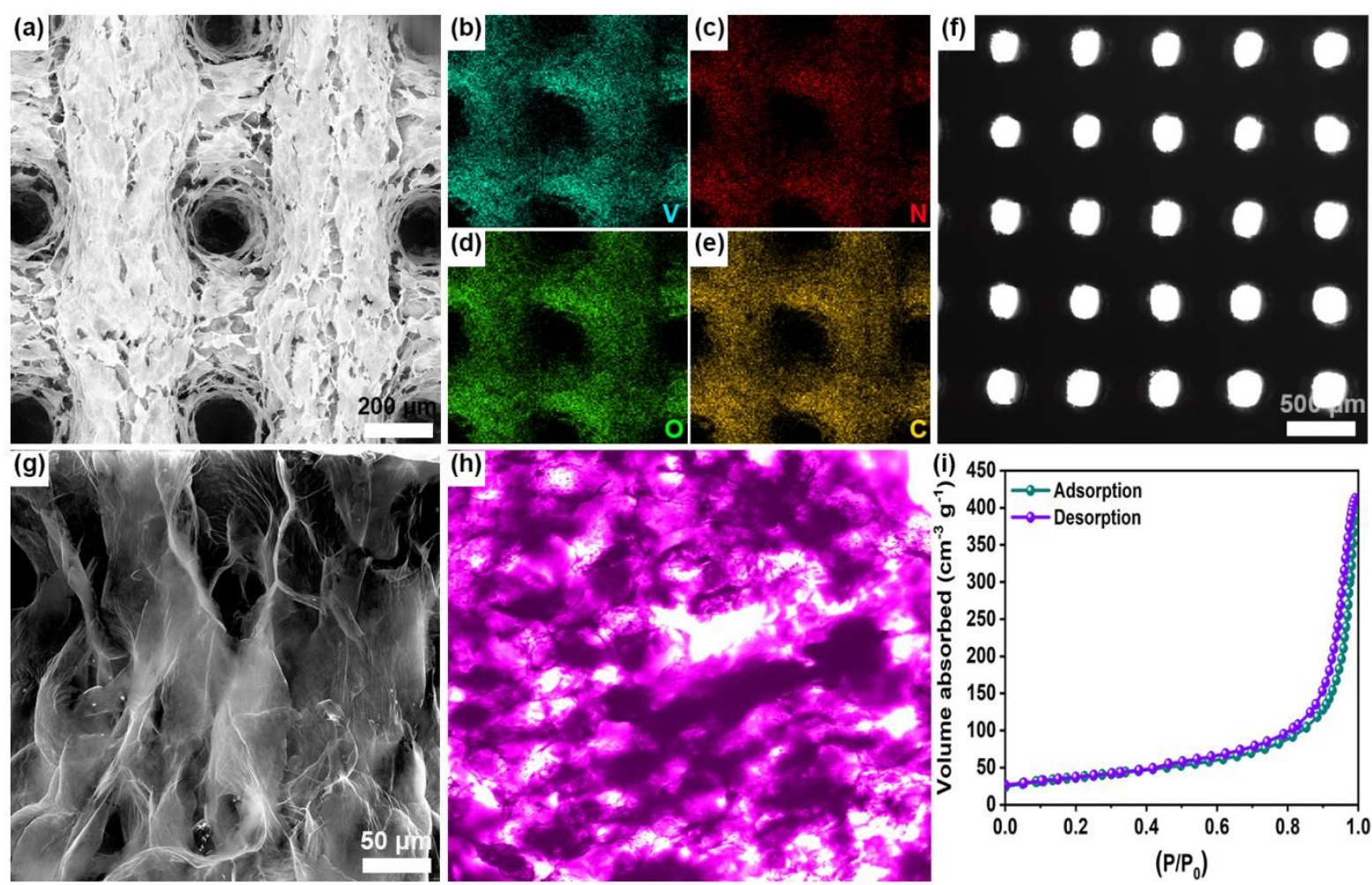

Figure S10. (a, b) SEM images, (c-f) EDX images of the V, O, N and C elements in (a), (g, h) LCSM images and (i) $\mathrm{N}_{2}$ adsorption/desorption isotherm of the 3D-printed C60@VNNWs@rGO microlattices and its gradient porous structure. 
(a)

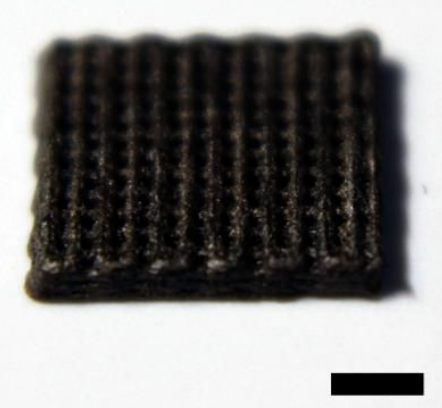

(c)

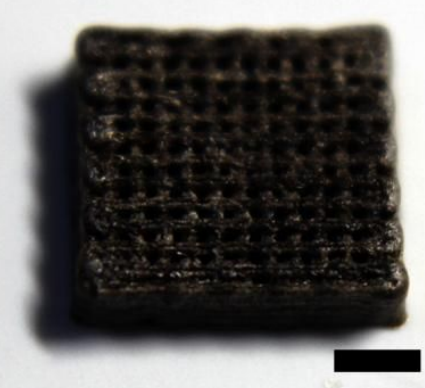

(b)

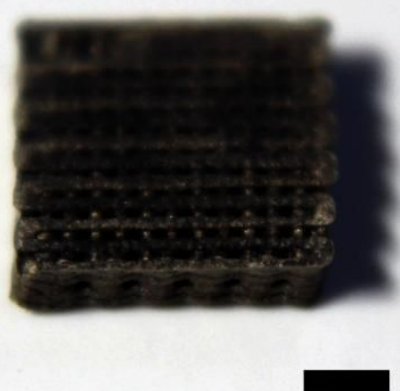

(d)

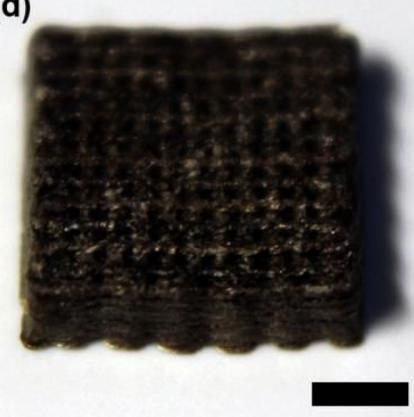

Figure S11. Photographs of the as-fabricated Cu/Co-THQ@CNTs@rGO microlattice electrode with 4 layer (a), 8 layer (b), 12 layer (c) and 16 layer (d). Scale bars, $2 \mathrm{~mm}$. 


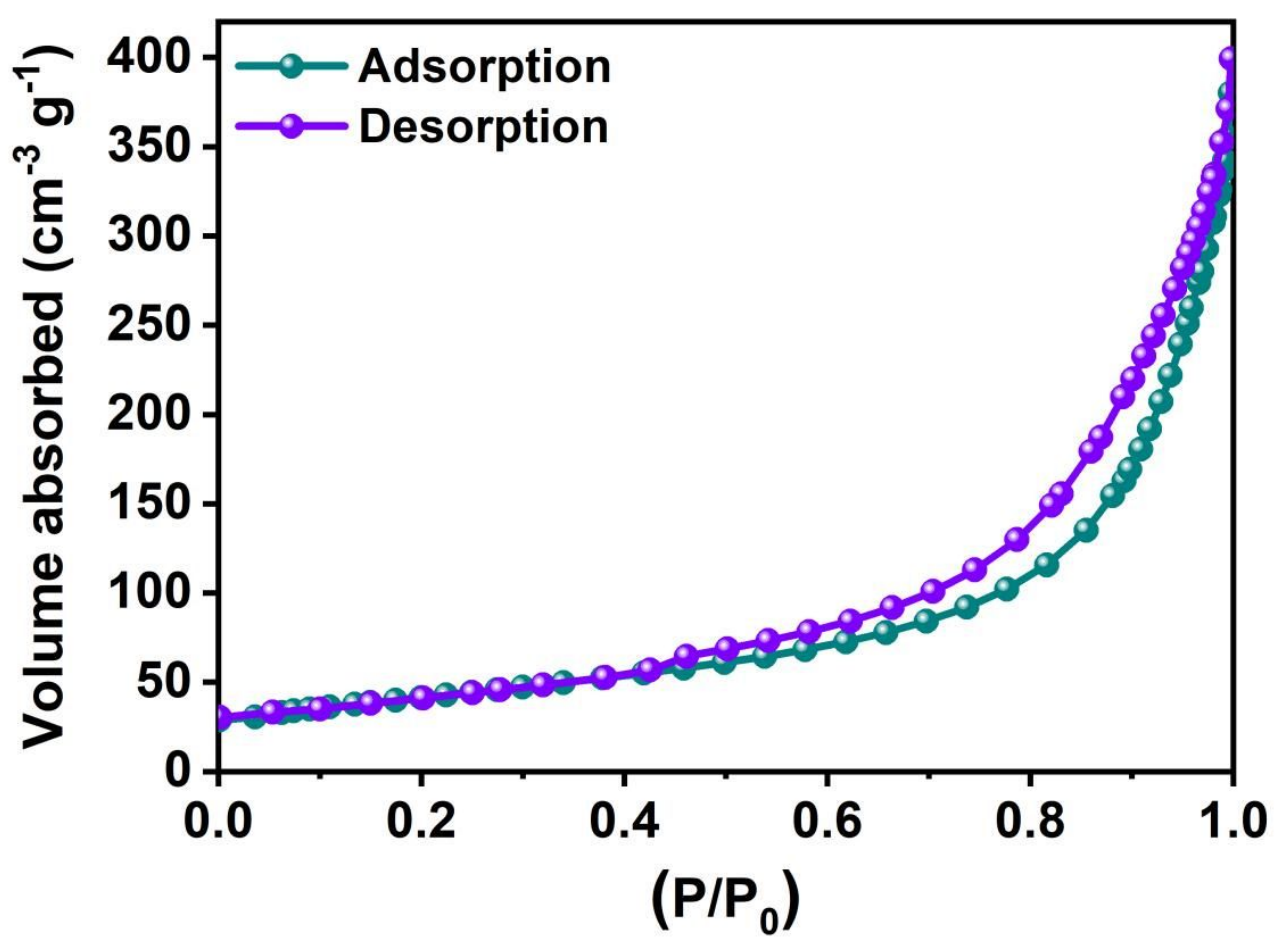

Figure S12. $\mathrm{N}_{2}$ adsorption/desorption isotherm of the 3D-printed Cu/Co-THQ@CNTs@rGO microlattices and its gradient porous structure. 


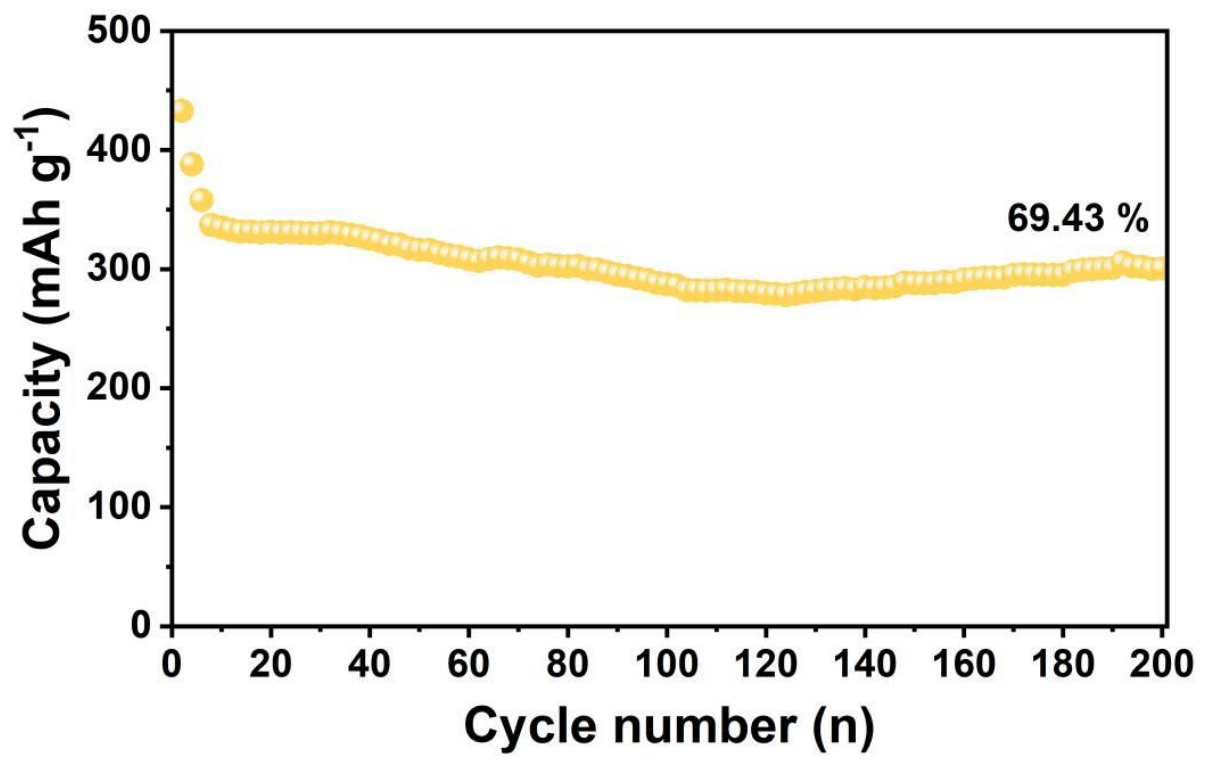

Figure S13. Cycling performance of the 3D-printed Cu/Co-THQ@CNTs@rGO microlattice electrode at $0.1 \mathrm{~A} \mathrm{~g}^{-1}$. 


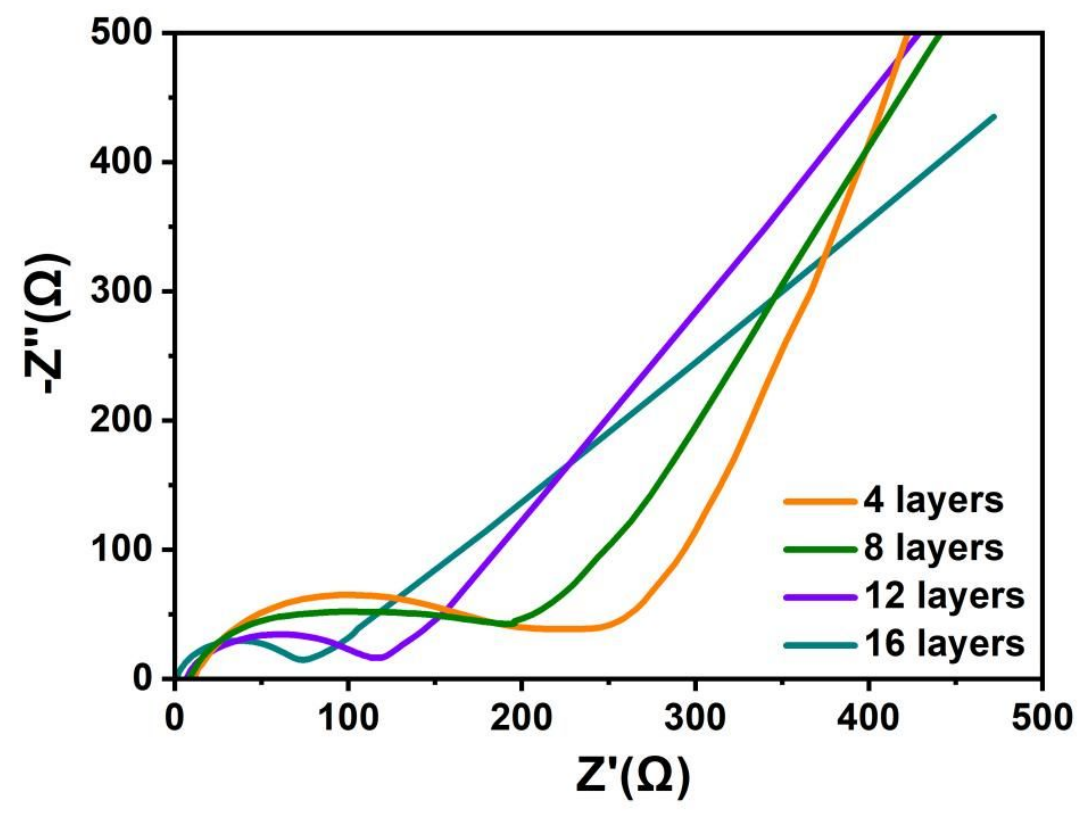

Figure S14. Nyquist plots of the 3D-printed Cu/Co-THQ@CNTs@rGO microlattice electrodes with different layers. 

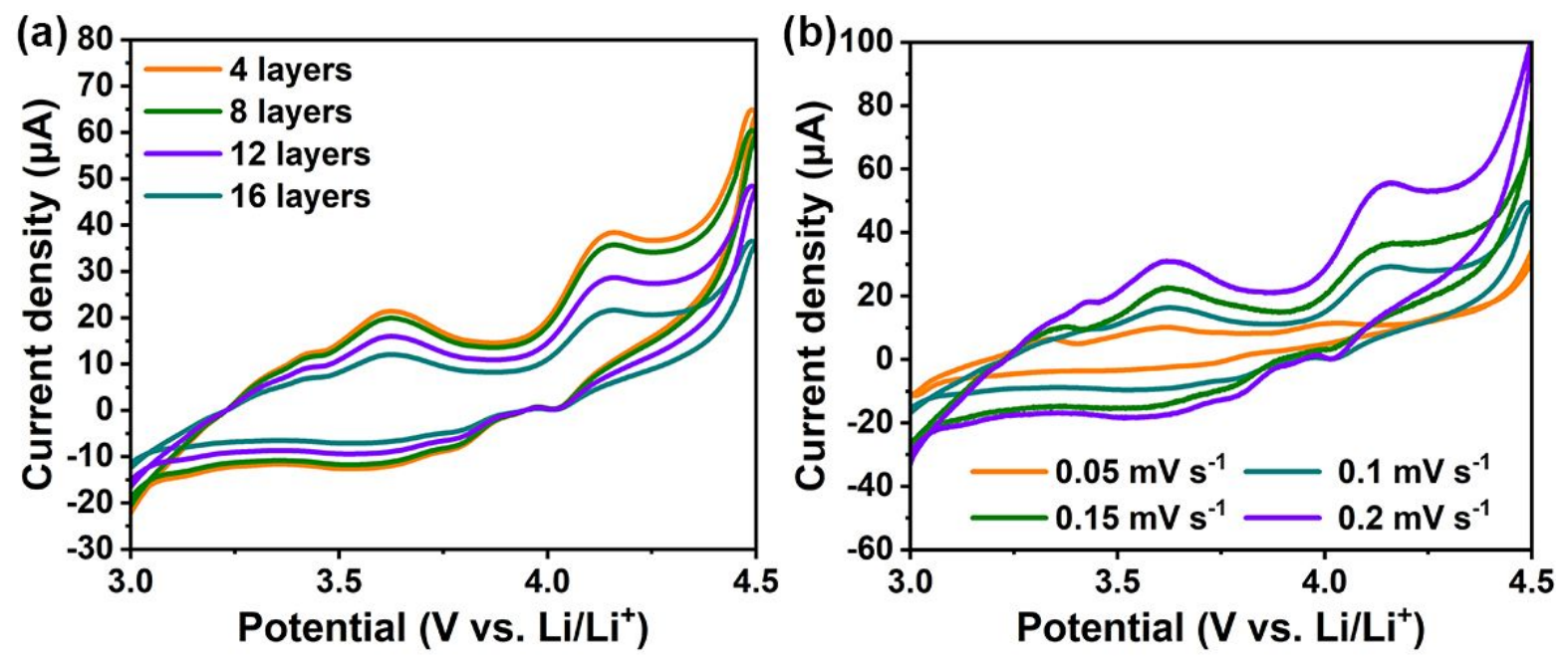

Figure S15. (a) CV curves of the 3D-printed Cu/Co-THQ@CNTs@rGO microlattice electrodes with different layers at $0.1 \mathrm{mV} \mathrm{s}^{-1}$. (b) $\mathrm{CV}$ curves of the 3D-printed Cu/Co-THQ@CNTs@rGO microlattice electrode at various scan rates from 0.05 to 0.2 $\mathrm{mV} \mathrm{s}^{-1}$. 

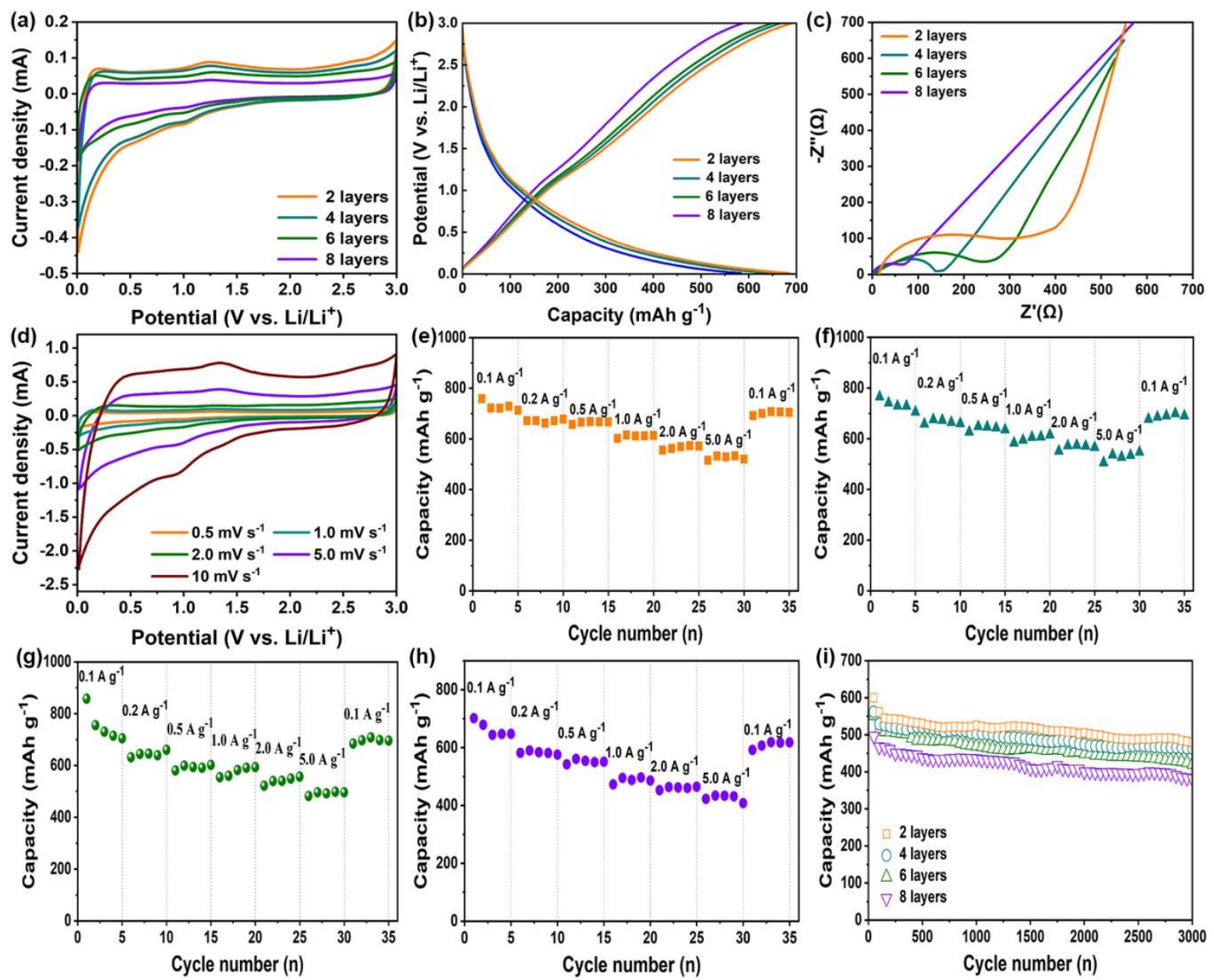

Figure S16. Electrochemical performance of the C60@VNNWs@rGO microlattice electrode. (a) CV curves of the 3D-printed electrodes with different layers at $0.5 \mathrm{mV} \mathrm{s}^{-1}$. (b) The typical charging/discharging of the 3D-printed electrodes with different layers with the potential window of $0.01-3 \mathrm{~V}\left(\mathrm{vs} \mathrm{Li} / \mathrm{Li}^{+}\right)$at $0.2 \mathrm{~A} \mathrm{~g}^{-1}$. (c) Nyquist plots of the 3D-printed electrodes with different layers. (d) CV curves of the 3D-printed electrode with 12 layers at various scan rates from 0.5 to $10 \mathrm{mV} \mathrm{s}^{-1}$. (e-h) Rate capability of the 3D-printed electrodes with different layers $(2,4,6$ and 8 layer) at various current densities ranging from 0.1 to $5 \mathrm{~A} \mathrm{~g}^{-1}$, respectively. (i) Cycling performance of the 3D printed electrodes with different layers at $5 \mathrm{~A} \mathrm{~g}^{-1}$. 

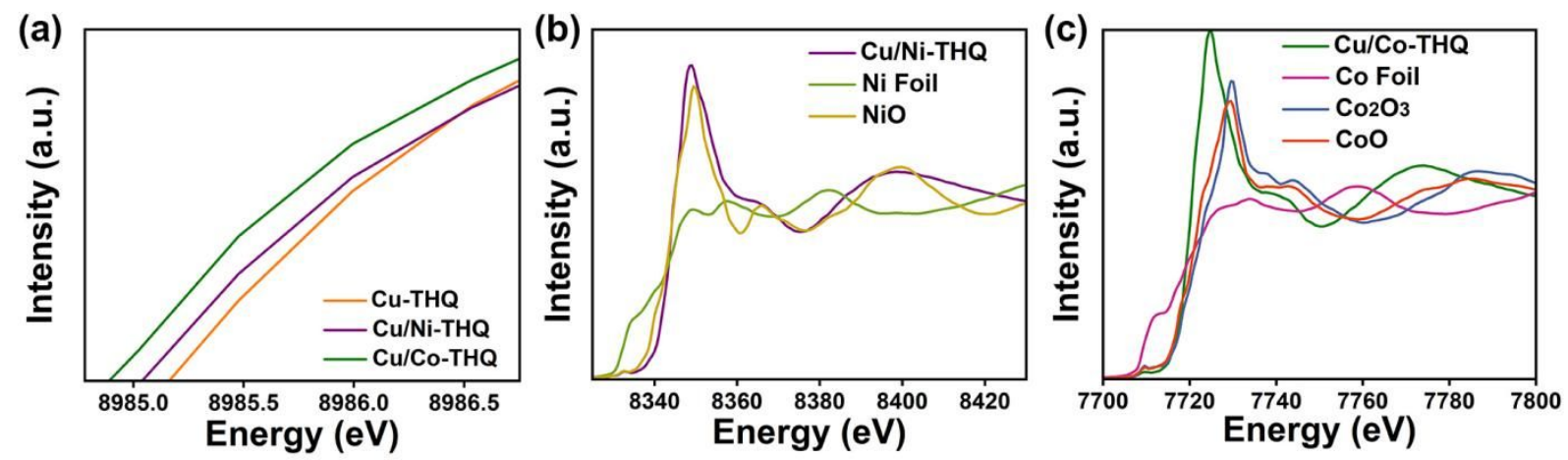

Figure S17. (a) The enlarged $\mathrm{Cu}$ K-edge XANES curves of $\mathrm{Cu}-\mathrm{THQ}, \mathrm{Cu} / \mathrm{Ni}$-THQ and $\mathrm{Cu} / \mathrm{Co}-\mathrm{THQ}$. (b) Ni K-edge XANES spectra of $\mathrm{Cu} / \mathrm{Ni}-\mathrm{THQ}$ and references. (c) Co K-edge XANES spectra of $\mathrm{Cu} / \mathrm{Co}-\mathrm{THQ}$ and references. 

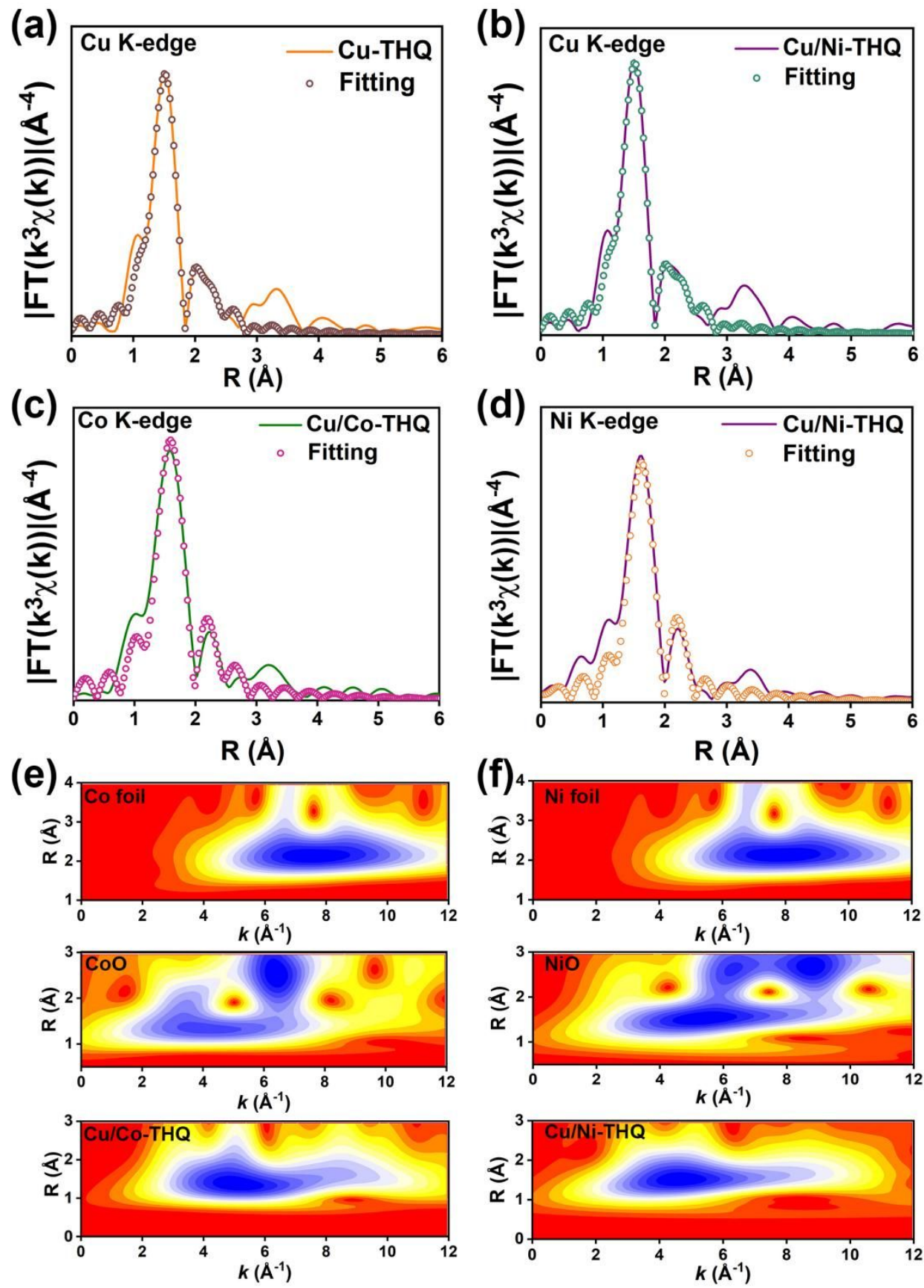

Figure S18. The typical fitting curve of the EXAFS signal in $\mathrm{Cu} \mathrm{K}$-edge for (a) $\mathrm{Cu}-\mathrm{THQ}$ and (b) $\mathrm{Cu} / \mathrm{Ni}$-THQ. The typical fitting curve of the EXAFS signal in (c) Co K-edge for $\mathrm{Cu} / \mathrm{Co}-\mathrm{THQ}$ and (d) Ni K-edge for $\mathrm{Cu} / \mathrm{Ni}$-THQ. (e, f) WT contour plots of $\mathrm{Cu} / \mathrm{Co}-\mathrm{THQ}$, $\mathrm{Cu} / \mathrm{Ni}-\mathrm{THQ}$ and references. 

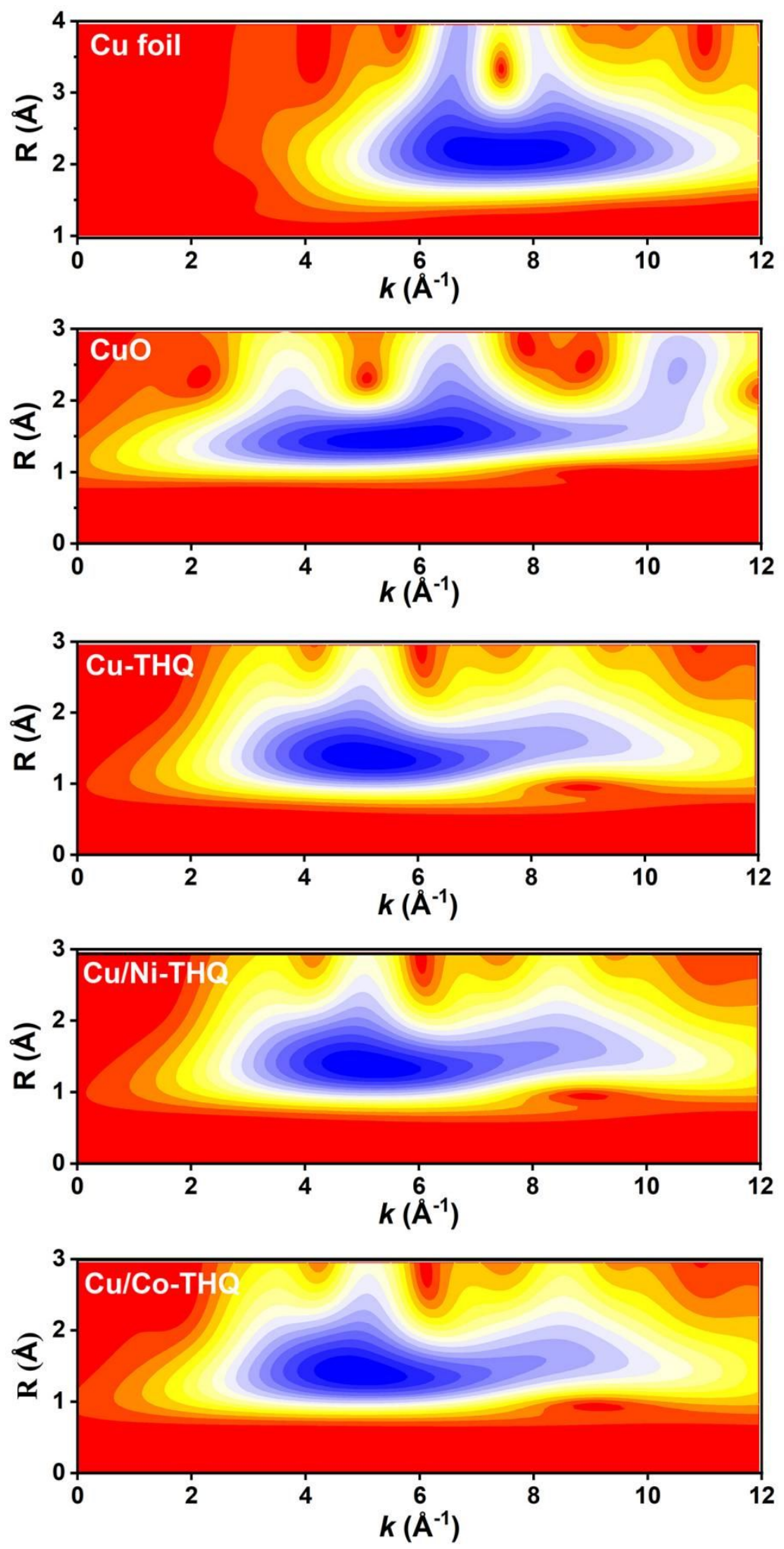

Figure S19. WT contour plots of $\mathrm{Cu}-\mathrm{THQ}, \mathrm{Cu} / \mathrm{Ni}-\mathrm{THQ}, \mathrm{Cu} / \mathrm{Co}-\mathrm{THQ}$ and references. 

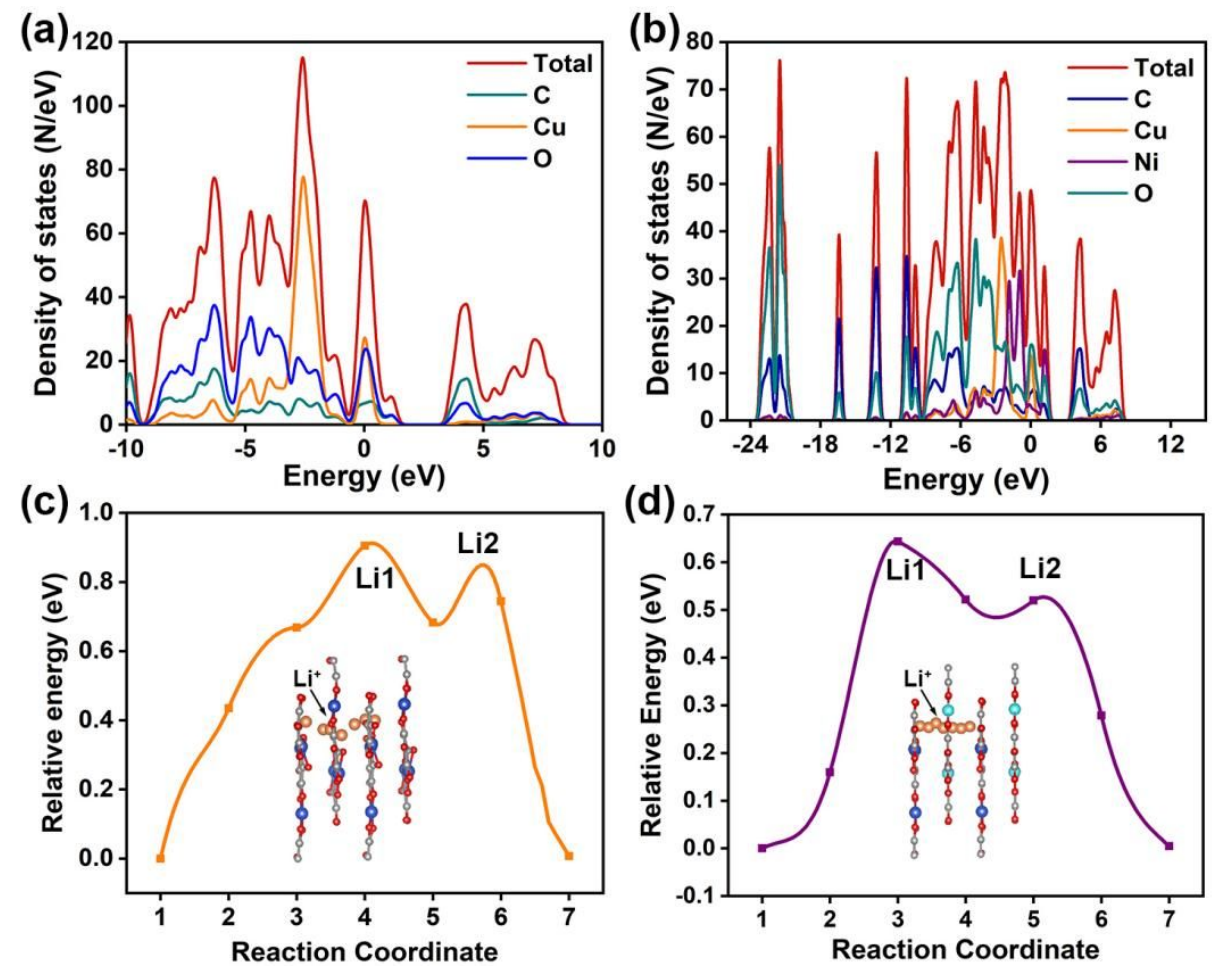

Figure S20. Density of states for (a) $\mathrm{Cu}-\mathrm{THQ}$ and $\mathrm{Cu} / \mathrm{Ni}-\mathrm{THQ}$. Energy barrier profile of $\mathrm{Li}^{+}$migration through (c) Cu-THQ and (d) $\mathrm{Cu} / \mathrm{Ni}-\mathrm{THQ}$. The insets are the corresponding migration process. 


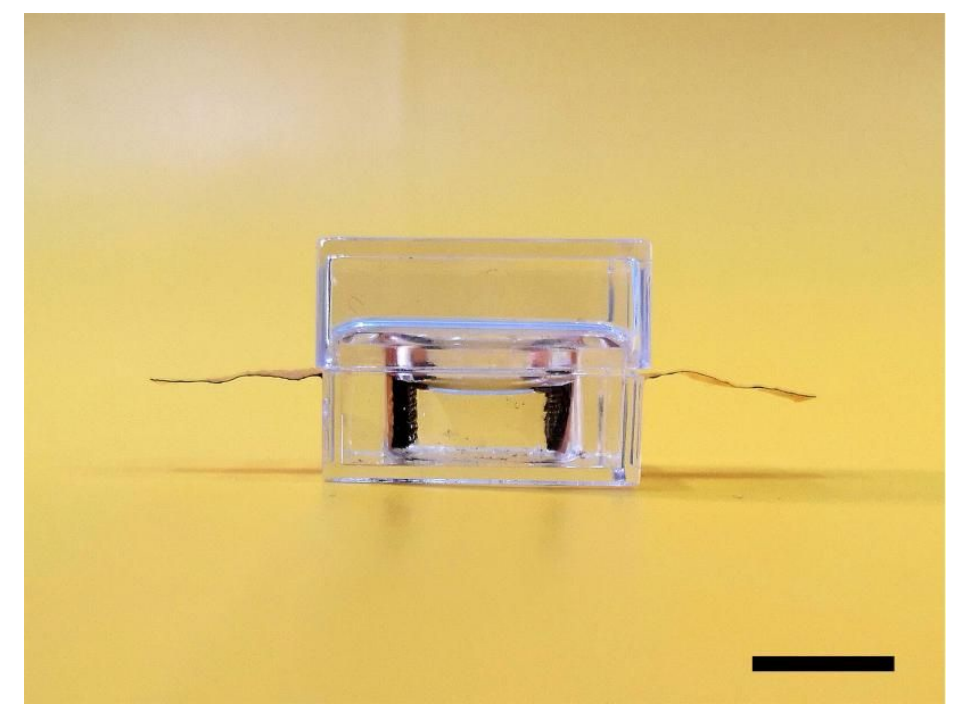

Figure S21. The digital photo of the 3D-printed LIHCs device. Scale bars: $1 \mathrm{~cm}$. 

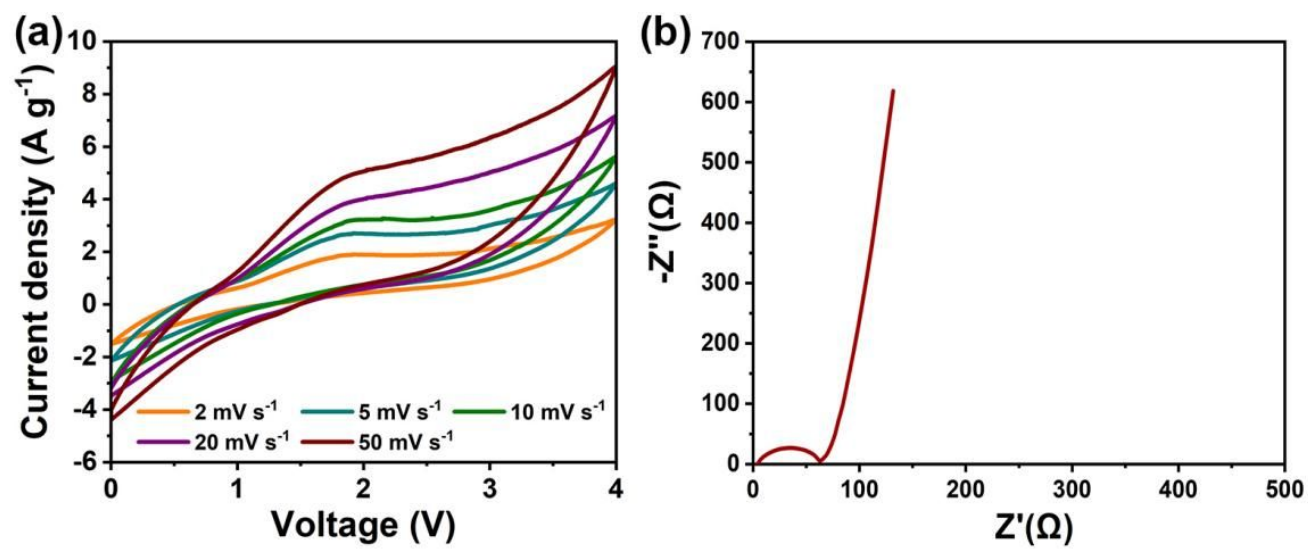

Figure S22. (a) CV curves of the 3D-printed LIHCs device at various scan rates from 2 to 50 $\mathrm{mV} \mathrm{s}^{-1}$. (b) Nyquist plot of the 3D-printed LIHCs device. 


\begin{tabular}{|c|c|c|c|c|c|c|}
\hline Sample & Coordination & $\mathbf{C N}$ & $\mathbf{R}(\AA ̊)$ & $\sigma^{2}\left(\times 10^{-3} \AA^{2}\right)$ & $\Delta E(e V)$ & R-factor \\
\hline $\mathrm{Cu}$ foil & $\mathrm{Cu}-\mathrm{Cu}$ & 12 & 2.55 & 1 & 1 & 1 \\
\hline $\mathrm{CuO}$ & $\mathrm{Cu}-\mathrm{O}$ & 4 & 1.95 & 1 & 1 & 1 \\
\hline $\mathrm{Cu}_{2} \mathrm{O}$ & $\mathrm{Cu}-\mathrm{O}$ & 2 & 1.85 & 1 & 1 & 1 \\
\hline \multirow{2}{*}{$\mathrm{Cu}-\mathrm{THQ}$} & $\mathrm{Cu}-\mathrm{O}$ & 4.3 & 1.94 & 4.9 & -0.4 & \multirow{2}{*}{$0.29 \%$} \\
\hline & $\mathrm{Cu}-\mathrm{C}$ & 2.2 & 2.69 & 3.3 & 4.6 & \\
\hline \multirow{2}{*}{$\mathrm{Cu} / \mathrm{Co}-\mathrm{THQ}$} & $\mathrm{Cu}-\mathrm{O}$ & 4.3 & 1.94 & 4.7 & 2.1 & \multirow{2}{*}{$0.33 \%$} \\
\hline & $\mathrm{Cu}-\mathrm{C}$ & 2.6 & 2.70 & 3.6 & 6.7 & \\
\hline \multirow{2}{*}{$\mathrm{Cu} / \mathrm{Ni}-\mathrm{THQ}$} & $\mathrm{Cu}-\mathrm{O}$ & 4.3 & 1.94 & 4.6 & -0.3 & \multirow{2}{*}{$0.30 \%$} \\
\hline & $\mathrm{Cu}-\mathrm{C}$ & 2.3 & 2.70 & 3.0 & 4.8 & \\
\hline
\end{tabular}

Table S1. Structural parameters of the sample obtained from the XAFS fitting at $\mathrm{Cu}$ K-edge. 
Table S2. Structural parameters of the sample obtained from the XAFS fitting at Co K-edge.

\begin{tabular}{|c|c|c|c|c|c|c|}
\hline Sample & Coordination & $\mathbf{C N}$ & $\mathbf{R}(\AA)$ & $\sigma^{2}\left(\times 10^{-3} \AA^{2}\right)$ & $\Delta E(e V)$ & R-factor \\
\hline Co foil & Co-Co & 12 & 2.50 & 1 & 1 & 1 \\
\hline $\mathrm{Co}_{2} \mathrm{O}_{3}$ & $\mathrm{Co}-\mathrm{O}$ & 6 & 2.09 & 1 & 1 & 1 \\
\hline $\mathrm{CoO}$ & $\mathrm{Co}-\mathrm{O}$ & 6 & 2.133 & 1 & 1 & 1 \\
\hline \multirow{2}{*}{$\mathrm{Cu} / \mathrm{Co}-\mathrm{THQ}$} & $\mathrm{Co}-\mathrm{O}$ & 4.4 & 2.07 & 3.0 & -3.4 & \multirow{2}{*}{$1.65 \%$} \\
\hline & $\mathrm{Co}-\mathrm{C}$ & 8.0 & 2.75 & 11.3 & -4.9 & \\
\hline
\end{tabular}


Table S3. Structural parameters of the sample obtained from the XAFS fitting at Ni K-edge.

\begin{tabular}{|c|c|c|c|c|c|c|}
\hline Sample & Coordination & $\mathbf{C N}$ & $\mathbf{R}(\mathbf{\AA})$ & $\begin{array}{c}\boldsymbol{\sigma}^{\mathbf{2}}\left(\times \mathbf{1 0}^{-3}\right. \\
\left.\AA^{\mathbf{2}}\right)\end{array}$ & $\boldsymbol{\Delta} \mathbf{E}(\mathbf{e V})$ & $\mathbf{R}$-factor \\
\hline Ni foil & $\mathrm{Ni}-\mathrm{Ni}$ & 12 & 2.49 & $\backslash$ & $\backslash$ & $\backslash$ \\
\hline $\mathrm{NiO}$ & $\mathrm{Ni}-\mathrm{O}$ & 6 & 2.08 & $\backslash$ & $\backslash$ & 1 \\
\hline \multirow{2}{*}{$\begin{array}{c}\mathrm{Cu} / \mathrm{Ni}- \\
\mathrm{THQ}\end{array}$} & $\mathrm{Ni}-\mathrm{O}$ & 4.5 & 2.05 & 2.3 & 4.9 & \multirow{2}{*}{$1.65 \%$} \\
\cline { 2 - 6 } & $\mathrm{Ni}-\mathrm{C}$ & 5 & 2.71 & 9.0 & -1.8 & \\
\hline
\end{tabular}


Table S4. The electrical conductivity of $\mathrm{Cu}-\mathrm{THQ}, \mathrm{Cu} / \mathrm{Co}-\mathrm{THQ}$ and $\mathrm{Cu} / \mathrm{Ni}-\mathrm{THQ}$.

\begin{tabular}{cc}
\hline Samples & Conductivity $\left(\mu \mathrm{S} \cdot \mathrm{cm}^{-1}\right)$ \\
\hline $\mathrm{Cu}$-THQ & $0.18 \pm 0.03$ \\
$\mathrm{Cu} / \mathrm{Co}-\mathrm{THQ}$ & $0.41 \pm 0.07$ \\
$\mathrm{Cu} / \mathrm{Ni}$-THQ & $0.32 \pm 0.05$ \\
\hline
\end{tabular}

\section{References}

[1] Park, J.; Hinckley, A.; Huang, Z.; Feng, D.; Yakovenko, A.; Lee, M.; Chen, S.; Zou, X.; Bao, Z. Synthetic Routes for a 2D Semiconductive Copper Hexahydroxybenzene Metal-Organic Framework. J. Am. Chem. Soc. 2018, 140, 14533-14537.

[2] Wang, R.; Lang, J.; Zhang, P.; Lin, Z.; Yan, X. Fast and Large Lithium Storage in 3D Porous VN Nanowires-Graphene Composite as a Superior Anode Toward High-Performance Hybrid Supercapacitors. Adv. Funct. Mater. 2015, 25, 2270-2278.

[3] Zhao, J.; Zhang, Y.; Zhao, X.; Wang, R.; Xie, J.; Yang, C.; Wang, J.; Zhang, Q.; Li, L.; Lu, C.; Yao, Y. Direct Ink Writing of Adjustable Electrochemical Energy Storage Device with High Gravimetric Energy Densities. Adv. Funct. Mater. 2019, 29, 1900809.

[4] Kresse, G.; Furthmüller, J. Efficient iterative schemes for ab initio total-energy calculations using a plane-wave basis set. Phys. Rev. B 1996, 54, 11169.

[5] Kresse, G.; Hafner, J. Ab initio molecular dynamics for liquid metals. Phys. Rev. $B$ 1993, 47, 558 .

[6] Perdew, J.; Burke, K.; Ernzerhof, M. Generalized Gradient Approximation Made Simple. Phys. Rev. Lett. 1996, 77, 3865. 
[7] Kresse, G.; Joubert, D. From ultrasoft pseudopotentials to the projector augmented-wave method. Phys. Rev. B 1999, 59, 1758.

[8] Blöchl P. Projector augmented-wave method. Phys. Rev. B 1994, 50, 17953.

[9] Monkhorst, H.; Pack, J. Special points for Brillouin-zone integrations. Phys. Rev. $B$ 1976, 13, 5188 .

[10] Sheppard, D.; Henkelman, G. Paths to which the nudged elastic band converges. J. Comp. Chem. 2011, 32, 1769.

[11] Sheppard, D.; Xiao, P.; Chemelewski, W.; Johnson, D.; Henkelman, G. A generalized solid-state nudged elastic band method. J. Chem. Phys. 2012, 136, 074103. 